\title{
PSMA-homing dsRNA chimeric protein vector kills prostate cancer cells and activates anti-tumor bystander responses
}

\author{
Yael Langut ${ }^{1}$, Nufar Edinger ${ }^{1}$, Efrat Flashner-Abramson ${ }^{1}$, Naomi Melamed-Book ${ }^{2}$, \\ Mario Lebendiker ${ }^{3}$, Yael Levi-Kalisman ${ }^{4}$, Shoshana Klein ${ }^{1}$ and Alexander Levitzki ${ }^{1}$ \\ ${ }^{1}$ Department of Biological Chemistry, Unit of Cellular Signaling, Silberman Institute of Life Sciences, Safra Campus, The \\ Hebrew University of Jerusalem, Jerusalem, Israel \\ ${ }^{2}$ Department of Biological Chemistry, Unit of Bio-Imaging, Silberman Institute of Life Sciences, Safra Campus, The Hebrew \\ University of Jerusalem, Jerusalem, Israel \\ ${ }^{3}$ The Protein Purification Facility, Wolfson Center for Applied Structural Biology, Silberman Institute of Life Sciences, Safra \\ Campus, The Hebrew University of Jerusalem, Jerusalem, Israel \\ ${ }^{4}$ The Center for Nanoscience and Nanotechnology, Silberman Institute for Life Sciences, Safra Campus, The Hebrew \\ University of Jerusalem, Jerusalem, Israel
}

Correspondence to: Alexander Levitzki, email: alex.levitzki@mail.huji.ac.il

Keywords: PSMA, polyIC, dsRNA binding domain, ScFvJ591

Received: October 07, $2016 \quad$ Accepted: February 11, $2017 \quad$ Published: February 25, 2017

Copyright: Langut et al. This is an open-access article distributed under the terms of the Creative Commons Attribution License (CC-BY), which permits unrestricted use, distribution, and reproduction in any medium, provided the original author and source are credited.

\section{ABSTRACT}

The treatment of metastatic androgen-resistant prostate cancer remains a challenge. We describe a protein vector that selectively delivers synthetic dsRNA, polyinosinic/polycytidylic acid (polyIC), to prostate tumors by targeting prostate specific membrane antigen (PSMA), which is overexpressed on the surface of prostate cancer cells.

The chimeric protein is built from the double stranded RNA (dsRNA) binding domain of PKR tethered to a single chain anti-PSMA antibody. When complexed with polyIC, the chimera demonstrates selective and efficient killing of prostate cancer cells. The treatment causes the targeted cancer cells to undergo apoptosis and to secrete toxic cytokines. In a "bystander effect", these cytokines kill neighboring cancer cells that do not necessarily overexpress PSMA, and activate immune cells that enhance the killing effect. The strong effects of the targeted polyIC are demonstrated on both 2D cell cultures and 3D tumor spheroids.

\section{INTRODUCTION}

Prostate cancer is the second most commonly diagnosed cancer worldwide, accounting for over $25 \%$ of new cancer cases diagnosed annually among men in the US [1]. Patients with metastatic prostate cancer are usually treated with androgen deprivation therapy (ADT). While ADT generally achieves short-term remission, patients typically develop castration-resistant prostate cancer (CRPC). There is a great demand for novel therapies for CRPC patients, as these patients rarely respond to existing therapies and demonstrate median survival of about 3 years [2-4].

Current targeted cancer therapies delay, but rarely prevent, tumor progression. As tumor cells are genomically unstable, they eventually acquire mutations and genetic alterations that allow them to evade the therapy and develop resistance [5-7]. The rate of killing elicited by targeted agents is too slow, allowing the tumors to adapt to the therapy [8-10]. Additionally, tumors are heterogeneous and possess a number of different subpopulations [11-13]. Targeted therapies are directed at specific subpopulations, and therefore cannot be expected to eradicate the entire tumor. We believe that an effective targeted therapy must kill the multiple sub-populations of the tumor simultaneously and rapidly, to preclude the development of resistance.

We have recently developed a new and promising strategy to develop such anti-cancer agents. Our strategy is to deliver synthetic dsRNA, polyinosine/polycytosine acid (polyIC), specifically into cancer cells. In cells, polyIC mimics dsRNA viruses, invoking anti-viral defense systems that cause cellular apoptosis and trigger an innate immune response. Thus, specific delivery of polyIC into cancer cells leads to massive killing of the targeted cancer cells, and provokes an innate immune 
response against neighboring, untargeted cancer cells. The rapid destruction of tumors and the concurrent use of multiple killing pathways increase treatment robustness and impede the development of drug resistance. Specific delivery of polyIC is achieved by attaching polyIC molecules to a targeting ligand, which homes to a receptor that is overexpressed on the surface of the cancer cell. Receptor overexpression provides treatment selectivity, by discriminating between cancer and non-cancer cells.

The secretion of cytokines and chemokines in response to the presence of polyIC leads to "bystander effects", i.e. the killing of neighboring untargeted tumor cells. Thus, the treatment is potent even against heterogeneous tumors [14]. We define two types of bystander effects: (1) A direct bystander effect, whereby toxic cytokines secreted from the targeted cancer cells lead to the activation of apoptotic pathways in neighboring, untargeted cancer cells; (2) An immune-cell-mediated bystander effect, whereby chemokines secreted from targeted cancer cells recruit and activate immune cells, enhancing the killing of neighboring, untargeted cancer cells.

Metastatic CRPC typically presents a unique cell surface molecule that can be exploited for targeted therapy: prostate-specific membrane antigen (PSMA). PSMA is overexpressed at levels of up to 1000-fold at all Gleason scores $[15,16]$, while overexpression increases with tumor progression $[17,18]$. Despite the heterogeneous nature of the disease, primary tumors or metastases that are completely PSMA-negative are rare [19]. While the above findings support the notion that PSMA is a highly promising therapeutic target, no PSMAtargeted therapies are currently approved for clinical use. However, a few agents are in clinical trials [20-23]. PSMA behaves like a classical receptor, exhibiting rapid internalization and recycling upon ligand binding [24]. Thus, a therapeutic entity can be coupled to a PSMA ligand and internalized into prostate cancer cells. Indeed, a variety of PSMA-targeting ligands are being investigated for tumor imaging [25-27] and for the development of PSMA-targeted therapeutic agents [28-31].

In our laboratory we have developed chemical vectors to deliver polyIC to EGFR-overexpressing glioblastoma [32], breast cancer and vulval carcinoma [14], as well as HER-2-overexpressing breast cancer [33]. The targeted polyIC proved to be extremely efficient at killing tumors in vitro and in vivo, leading in some cases to complete tumor eradication $[14,32]$.

Herein we present a protein alternative, rather than a chemical vector, to target PolyIC to prostate cancer. A protein vector offers multiple advantages over the use of a complex polymeric chemical vector. Since it is composed of humanized proteins, the likelihood of immune response is significantly diminished. The protein has a precise structure, defined by the recombinant gene from which it is expressed, which increases its chances of meeting the requirements of clinical development and regulatory approval processes [34]. Our protein vector, dsRBSCP (dsRB-Arg $-\mathrm{ScFvJ}_{9}$ 51), is a chimeric protein that comprises: (a) a polyIC-binding moiety, consisting of two dsRNA binding domains (dsRBD) derived from human dsRNA-activated protein kinase (PKR); (b) a nine residue arginine linker $\left(\mathrm{Arg}_{9}\right)$, to facilitate endosomal escape following endocytosis, in accordance with the findings of He et al.[35, 36]; (c) a specific targeting moiety, consisting of anti-PSMA single-chain antibody, ScFvJ591 [29, 37]. We show that dsRB-SCP successfully binds polyIC and elicits a powerful and selective killing effect on PSMAoverexpressing prostate cancer cells.

\section{RESULTS}

\section{ScFvJ591 selectively targets PSMA- overexpressing prostate cancer cells and efficiently internalizes into the cells}

We first tested whether the single chain antibody ScFvJ591 [29] could be used as a homing ligand, as part of a chimeric protein. We generated pGFP-Arg $-\mathrm{ScFvJ}_{9}$ 91, encoding GFP as a tracking marker fused to the single chain antibody against PSMA, ScFvJ591. The GFP and $\mathrm{ScFV}$ moieties are connected by a linker encoding an endosomal escape sequence (Figure 1A). The 56kDa recombinant protein, GFP-SCP (GFP-Arg ${ }_{9}-\mathrm{ScFvJ}_{591}$ ), was expressed in E. coli and purified in a 3-step purification process, consisting of affinity purification followed by two steps of gel filtration (Experimental Procedures).

We examined the selectivity of GFP-SCP using confocal microscopy. We incubated the chimeric protein with LNCaP cells, which overexpress PSMA, and analyzed binding after 5 hours. PC3 and MCF7 cells, which do not express PSMA, served as negative controls. The confocal images demonstrated that GFP-SCP bound to LNCaP cells and was internalized, while no binding was evident to PC3 or MCF7 cells (Figure 1B). We next compared the uptake of GFP-SCP into LNCaP and MCF7 cells using flow cytometry. The accumulation of GFP-SCP was indicated by the fluorescence shift. As expected, the observed fluorescence levels correlated with the concentration of GFP-SCP (200nM versus $400 \mathrm{nM}$ ) and the incubation period (30 minutes versus 60 minutes) (Figure 1C). These results suggest time-dependent and dose-dependent internalization of GFP-SCP. In contrast, in MCF7 cells, which lack PSMA, no accumulation of GFP-SCP was observed (Figure 1C).

To monitor the localization of GFP-SCP, we incubated LNCaP cells with GFP-SCP and observed them using live-cell confocal microscopy. Initially, GFPSCP fluorescence was confined to the cell surface and no 
free diffusion was observed (Figure 1D). Minutes later, GFP-SCP entered the cell via endocytosis, as indicated by the appearance of small intracellular punctate structures (Figure 1D). Over time, these structures increased in number. Eventually, the fluorescence became more diffuse (Figure 1D), suggesting that the GFP might have escaped from the endosome and diffused to the cytosol. The accumulation of the GFP inside the cell increased linearly over the first 40 minutes after binding (Figure 1D). Thus, GFP-SCP was taken up quickly and selectively by PSMAoverexpressing cells.
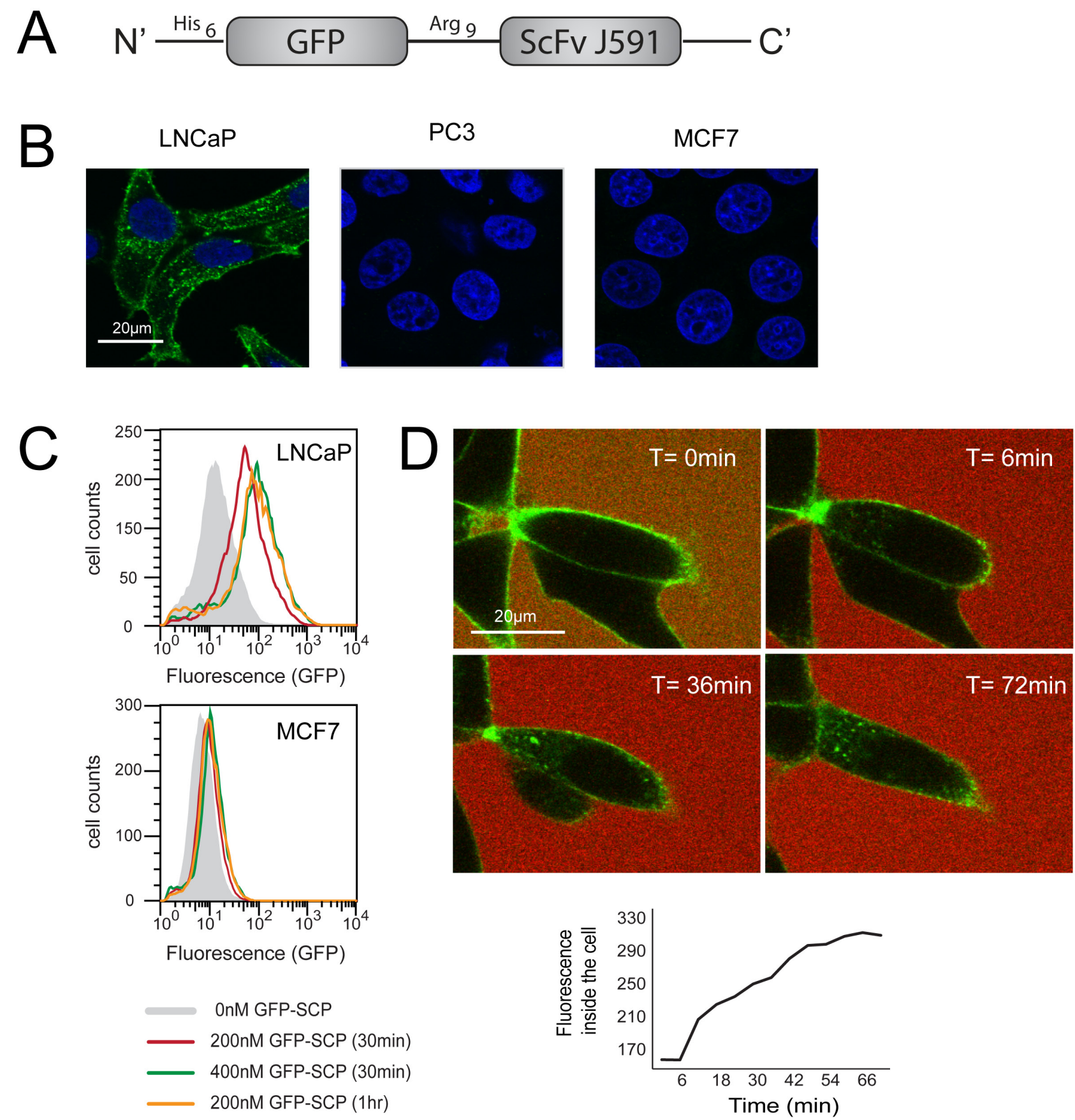

Figure 1: GFP-SCP binds and selectively internalizes into PSMA-overexpressing cells. A. Schematic representation of GFPSCP. B. LNCaP, PC3 and MCF7 cells were incubated with 25nM GFP-SCP for $5 \mathrm{~h}$. The cells were fixed and stained with anti-GFP antibody (Cy3) and 4, 6-diamidino-2-phenylindole and viewed by laser scanning confocal microscopy. C. LNCaP and MCF7 cells were incubated with GFP-SCP as indicated, then subjected to flow cytometric analysis. D. LNCaP cells were monitored by laser confocal imaging, 0 to 72 min after the addition of 200nM GFP-SCP. Sulforhodamine-B was added to the medium immediately before adding the GFP-SCP, to mark the outside of the cells. The graph shows GFP fluorescence inside the cell, as measured using ImageJ. 


\section{Production of a chimeric protein to deliver polyIC selectively to PSMA-overexpressing prostate cancer cells}

Once we had verified that the single chain antibody ScFvJ591 could specifically target PSMA-overexpressing cells, we designed a chimeric protein in which ScFvJ591 was fused with the two dsRNA-binding domains (dsRBD) of the human dsRNA-dependent protein kinase, PKR (Figure 2A). The $48 \mathrm{kDa}$ chimeric protein, dsRB-SCP (dsRB-Arg 9 -ScFvJ591), was expressed in E. coli, purified on nickel sepharose as a partially unfolded protein, refolded on the column, eluted and submitted to ion exchange, as described in the experimental procedures (Figure 2B).

To evaluate binding to dsRNA, dsRB-SCP was incubated with dsRNA of defined length (500 bp) and the mixture was electrophoresed on an agarose gel. The electrophoresis of dsRNA that was incubated with dsRB$\mathrm{SCP}$ at physiologic $\mathrm{pH}$ was retarded in a dose-dependent manner, relative to the naked dsRNA control (Figure 2C), confirming that the chimeric protein bound the dsRNA. On the other hand, dsRNA that was incubated with dsRB-
$\mathrm{SCP}$ at acidic $\mathrm{pH}$ migrated like naked dsRNA (Figure 2C). This indicates that the affinity of dsRB-SCP for dsRNA is low under acidic conditions, suggesting that dsRB-SCP can release its dsRNA cargo upon reaching the acidic environment of the endosome. The dsRB-SCP/polyIC complexes were visualized by cryo-transmission electron microscopy as distinct elongated structures, reminiscent of beads on a filament (Supplementary Figure 1). Similar structures were observed by Peisley et al., who looked at complexes of dsRNA and MDA5 protein [38]. These data confirm that dsRB-SCP can be used as a vector for dsRNA.

\section{dsRB-SCP complexed with polyIC selectively induces apoptosis in PSMA-overexpressing cells}

We next evaluated the killing effect of the dsRB$\mathrm{SCP} /$ polyIC complex using four cell lines: $\mathrm{LNCaP}$ and $\mathrm{VCaP}$, which overexpress PSMA, and MCF7 and PC3, which do not express PSMA. Cells that did not express PSMA were not killed by the treatment (Figure 3A). dsRB-SCP selectively delivered polyIC into the PSMAoverexpressing cells ( $\mathrm{LNCaP}$ and $\mathrm{VCaP}$ ), killing up to

\section{A N' His $_{6}$ dsRBD $\operatorname{Arg}_{9}$ ScFv J591 C'}

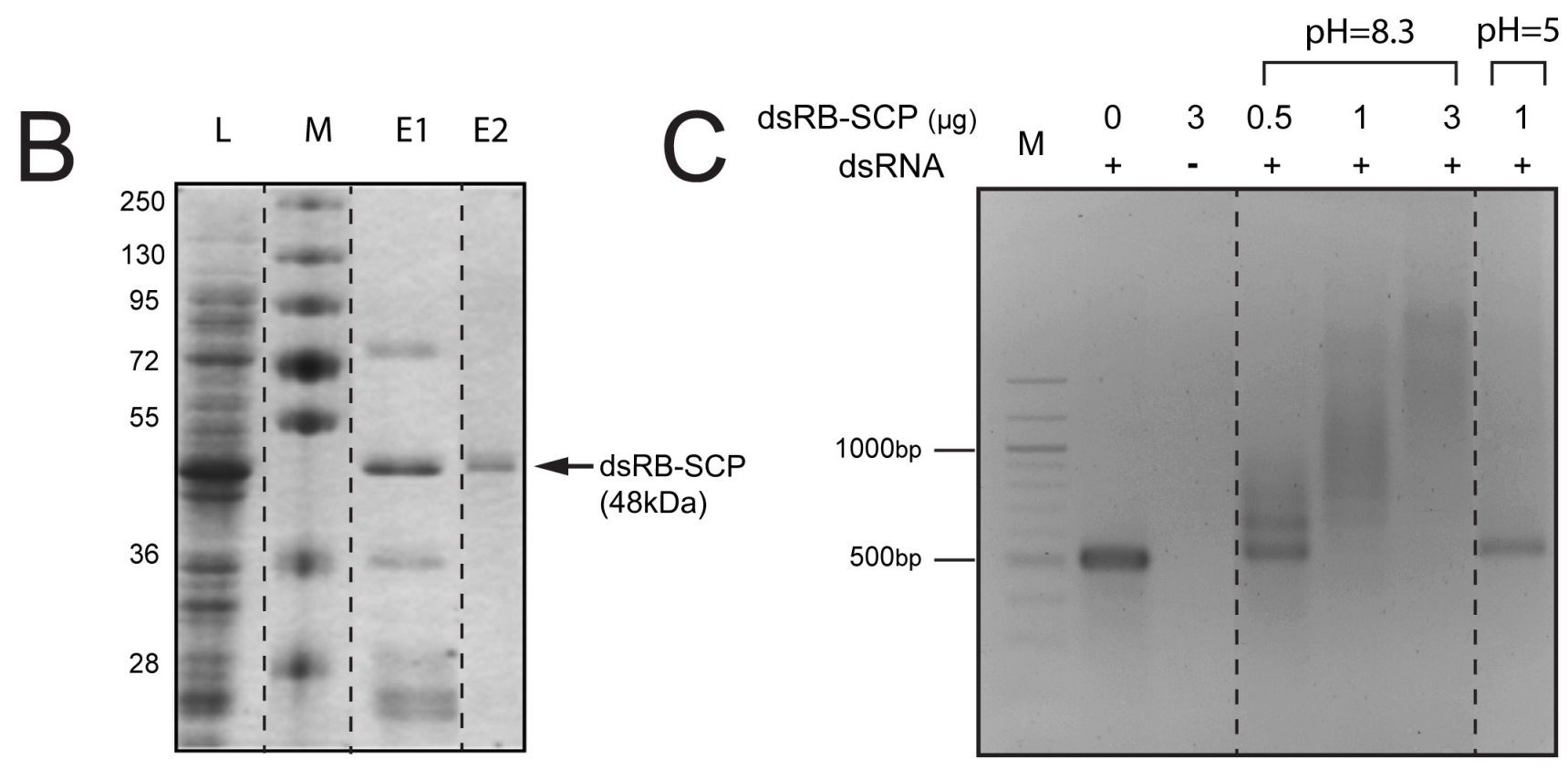

Figure 2: Design, expression and purification of dsRB-SCP. A. Schematic representation of dsRB-SCP. B. Expression and purification of dsRB-SCP: L: Cleared lysate, M: Molecular weight marker, E1: Eluate following IMAC (nickel sepharose column), E2: Purified dsRB-SCP eluted from IEX (ion exchange column). C. Binding of dsRB-SCP to dsRNA. dsRB-SCP (0.5-3 $\mu$ g) was preincubated with 500 bp long dsRNA in binding buffer at $\mathrm{pH} 8.3$ or $\mathrm{pH} 5$, and electrophoresed on a 2\% agarose gel. M: 100 bp DNA molecular weight marker. Dashed lines indicate where the pictures of the gels were cut and reorganized. 
$80 \%$ of the cells (Figure $3 \mathrm{~A}$ ). The remaining $20 \%$ of LNCaP cells were deemed permanently arrested, as no regrowth was observed 250 hours after washing out the chimera (350 hours after treatment) (Figure 3B). dsRB$\mathrm{SCP} /$ polyIC induced cell death by activating apoptotic pathways, as indicated by the cleavage of caspase- 3 and PARP (Figure 3C). In cells treated with polyIC alone, no cleavage of caspase- 3 or of PARP was detected (Figure $3 C)$. These data show that dsRB-SCP delivers polyIC selectively into PSMA-overexpressing cells, leading to their apoptosis.

\section{dsRB-SCP/polyIC treatment induces cytokine secretion and chemotaxis of immune cells}

The presence of dsRNA inside the cell activates the production of anti-proliferative and pro-apoptotic cytokines and chemokines [39]. To determine whether dsRB-SCP/polyIC can trigger similar effects we analyzed the production by LNCaP cells of three major cytokines: IP-10 and RANTES, which are both involved in the chemo-attraction of immune cells, and IFN- $\beta$, which plays a key role in the differentiation of immune cells [40]. The secretion of IP-10, RANTES and IFN- $\beta$ into the medium,

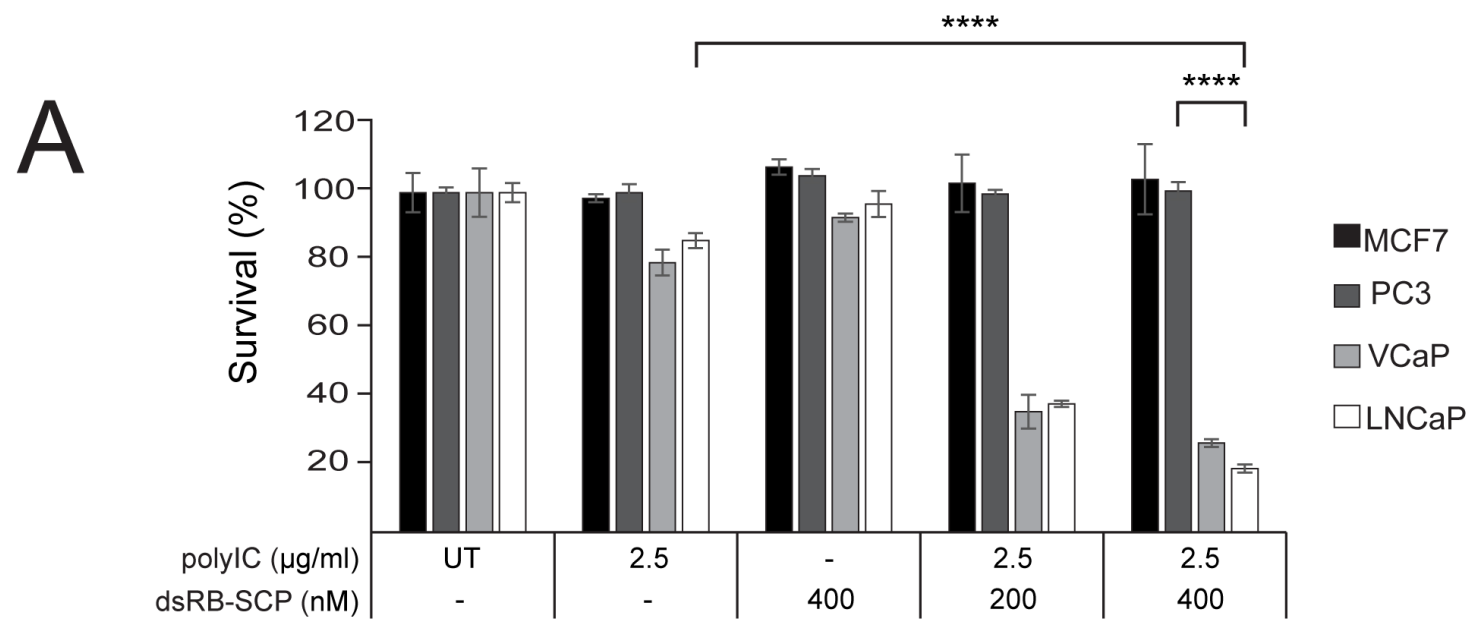

B
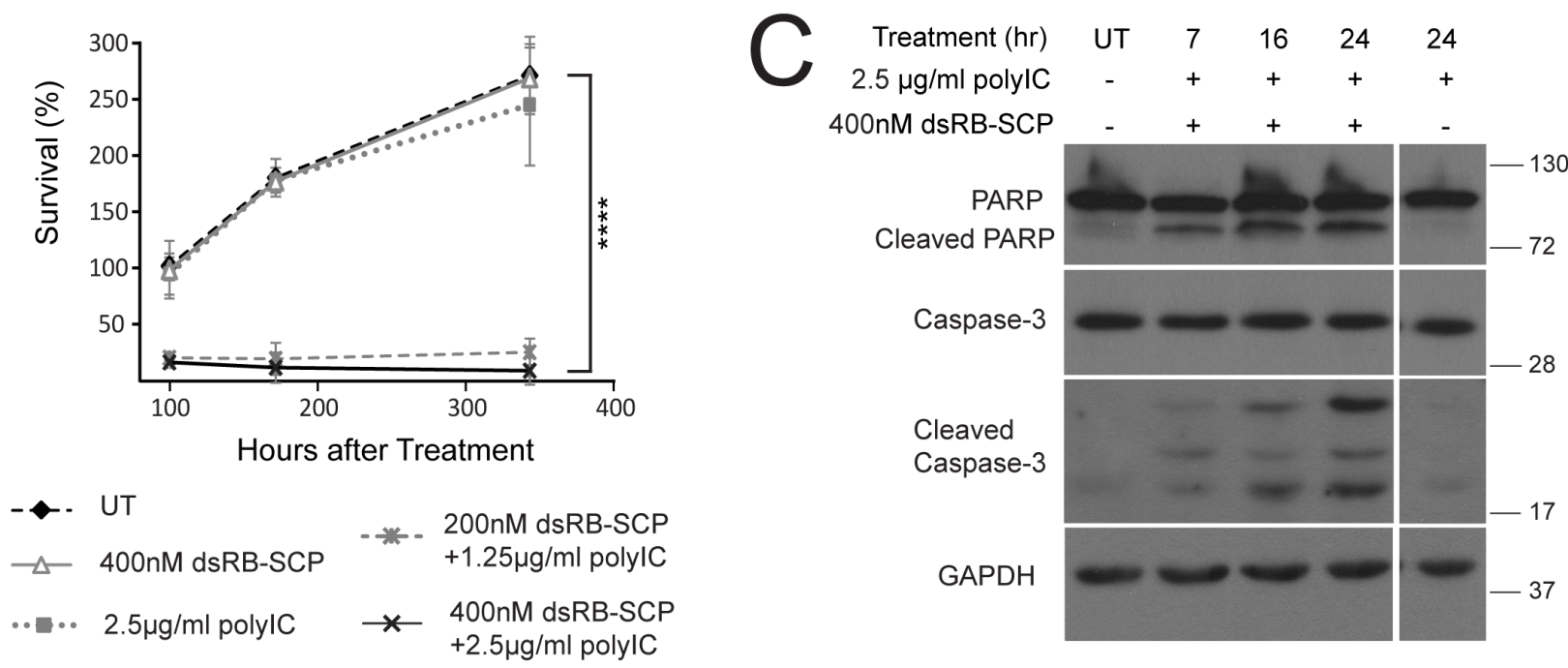

Figure 3: dsRB-SCP/polyIC selectively induces apoptosis of PSMA-overexpressing cells. A. Cells were seeded in triplicate, grown overnight, and treated with dsRB-SCP/polyIC, polyIC alone or dsRB-SCP alone, as indicated, for 100 h. Viability was quantified using the CellTiter-Glo Luminescent Cell Viability Assay (Promega). Results (mean and standard deviation) are representative of two independent experiments $(* * * * P \leq 0.0001$, treatment with dsRB-SCP/polyIC of LNCaP vs PC3; ****P $\leq 0.0001$ treatment of LNCaP with dsRB-SCP/polyIC vs polyIC alone). B. Surviving cells remained permanently arrested. Cells were seeded in triplicate, grown overnight, and treated as indicated. Medium was replaced and viability was quantified after 100/172/344 h using CellTiter-Glo ( $* * * * P \leq 0.0001 \mathrm{dsRB}-$ $\mathrm{SCP} /$ polyIC treatment vs UT). Control cells were unable to proliferate beyond 2.5 doublings because they had reached full confluence. $\mathbf{C}$. $\mathrm{LNCaP}$ cells were treated for the indicated times with dsRB-SCP/ polyIC or polyIC alone, lysed and subjected to western blot analysis to detect full-length and cleaved Caspase-3 and PARP. 
as measured by ELISA, was partially induced by polyIC alone, as reported previously [41]. Treatment with dsRB$\mathrm{SCP} /$ polyIC led to a further 2-fold increase in the secretion of all three cytokines (Figure 4A-4C). Similarly, IFN- $\beta$ expression was not affected by polyIC or dsRB-SCP alone, but treatment with dsRB-SCP/polyIC led to very strong induction of IFN- $\beta$ expression, as measured by qRT-PCR (Figure 4D).

To study whether the secreted cytokines attract immune cells, we examined whether the medium from dsRB-SCP/polyIC-treated LNCaP cells induced the chemotaxis of freshly isolated PBMCs. Almost four times
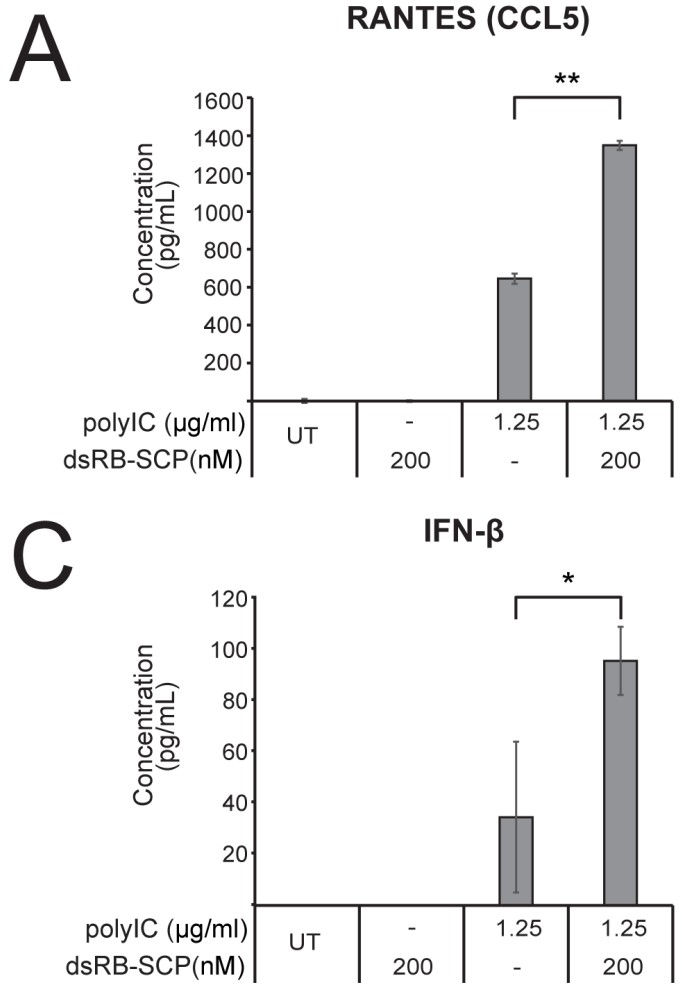

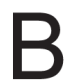

IP-10 (CXCL-10)

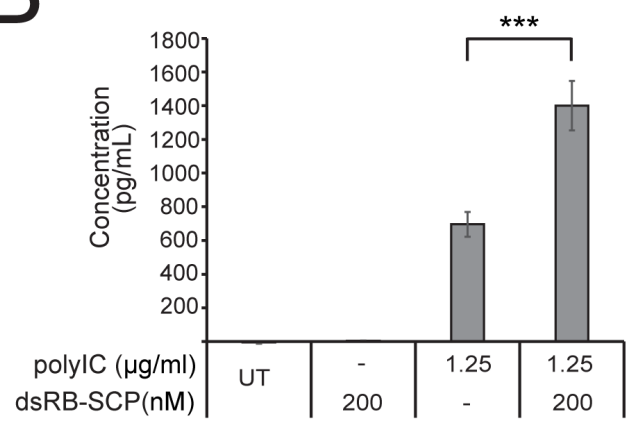

IFN- $\beta$
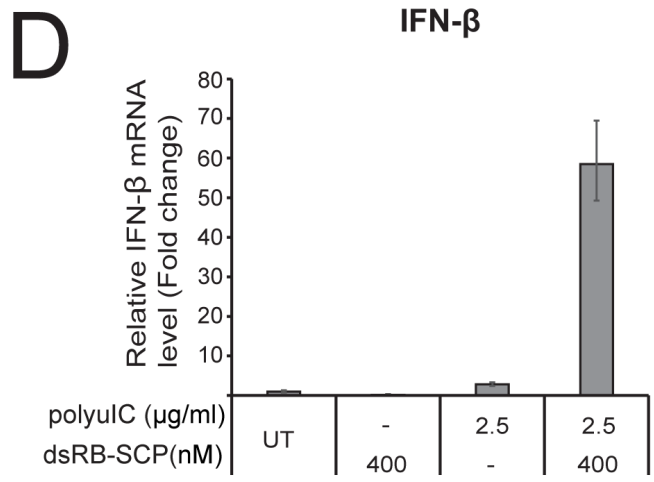

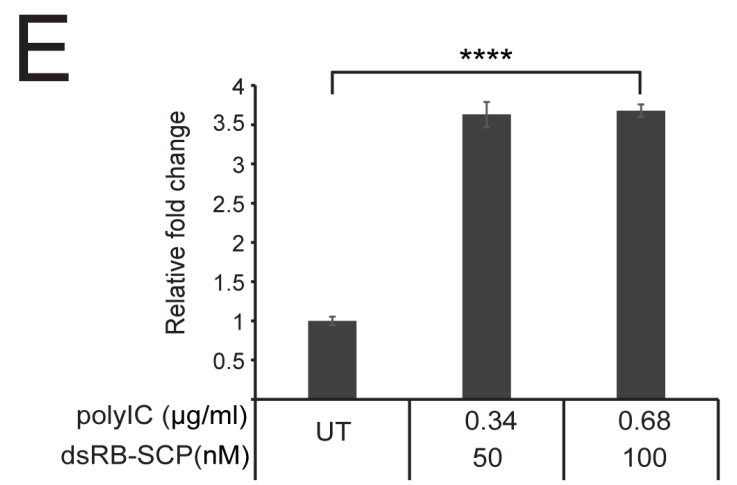

Figure 4: dsRB-SCP/polyIC leads to the secretion of pro-inflammatory cytokines and the recruitment of PBMCs. A.C. LNCaP cells were treated as indicated for $48 \mathrm{~h}$, after which medium was collected. IP-10, RANTES and IFN- $\beta$ in the medium were measured by ELISA assays. D. IFN- $\beta$ transcription was measured by qRT-PCR of LNCaP cells treated as indicated for $4 \mathrm{~h}$. Values are IFN- $\beta$ mRNA levels, normalized to GAPDH mRNA and expressed as fold change compared to untreated (UT) cells. All assays were conducted in triplicate and data are presented as mean concentration with standard deviation $(* * * P \leq 0.001, * * P \leq 0.01, * P \leq 0.05$, dsRB-SCP/ polyIC treatment vs polyIC alone). Results are representative of two independent experiments. E.. dsRB-SCP/ polyIC induces chemotaxis of PBMCs. LNCaP cells were grown and treated as indicated. $48 \mathrm{~h}$ after treatment, the cell medium was transferred to the lower chamber of a Transwell chemotaxis plate. PBMCs were added to the upper chamber, and the plates were incubated for $3.5 \mathrm{~h}$. Then, medium was collected from the lower chamber, in order to quantify lymphocytes that had migrated to the lower chamber. Lymphocytes in the collected medium were quantified by FACS. The number of lymphocytes that had migrated in the treated group is shown as mean fold change with standard deviation, relative to the number of cells that had migrated in the untreated group $(* * * * P \leq 0.0001$, dsRB-SCP/polyIC treatment vs untreated (UT)). 
as many PBMCs migrated towards conditioned medium from dsRB-SCP/polyIC-treated cells as towards medium from untreated cells (Figure 4E). Thus, targeted delivery of polyIC into PSMA-overexpressing cells leads to cytokine secretion and consequent immune cell chemo-attraction.

\section{Powerful bystander effects induced by dsRB-SCP/ polyIC}

We next tested whether the recruited immune cells could evoke an immune-cell-mediated bystander effect. We treated LNCaP-Luc/GFP cells, which stably express luciferase, with a low dose of dsRB-SCP/polyIC, followed by co-incubation with PBMCs. Luciferase activity served to measure the viability of the LNCaP-Luc/GFP cells. At the low doses used here, luciferase activity was barely affected when PBMCs were absent. In contrast, when PBMCs were added, the LNCaP-Luc/GFP cells were eradicated (Figure 5A). These results suggest that dsRB$\mathrm{SCP} /$ polyIC induces a powerful bystander effect, mediated by immune cells among the PBMCs.

To evaluate whether dsRB-SCP/polyIC also induces a direct bystander effect, LNCaP cells were co-incubated with PC3-Luc/GFP cells, which do not express PSMA. dsRB-SCP/polyIC treatment resulted in the killing of up to $60 \%$ of the PC3-Luc/GFP cells (Figure 5B). Since PC3-Luc/GFP cells are not targeted by dsRB-SCP/ polyIC (Figure 5B), we infer that the death of these cells is the result of a direct bystander effect elicited by the dsRB-SCP/polyIC-targeted LNCaP cells. The addition of human PBMCs to this co-culture system led to a significant increase in the killing rate of the PC3-Luc/GFP cells (Figure 5B), indicating that the direct and indirect bystander effects both operate under these conditions.

\section{dsRB-SCP/polyIC destroys tumor spheroids}

In vitro $3 \mathrm{D}$ models display some elements of the architecture of human tumors [42] and feature high resistance to anti-cancer drugs [43]. We therefore evaluated the efficacy of dsRB-SCP/polyIC in a $3 \mathrm{D}$ tumor spheroid model. LNCaP spheroids were generated and allowed to reach a diameter of 300-400 $\mu \mathrm{m}$. The spheroids were then transferred to polyHEMA-coated plates and treated repeatedly with dsRB-SCP/polyIC (400 nM dsRB$\mathrm{SCP}, 2.5 \mu \mathrm{g} / \mathrm{ml}$ polyIC) over the course of 5 days. By day
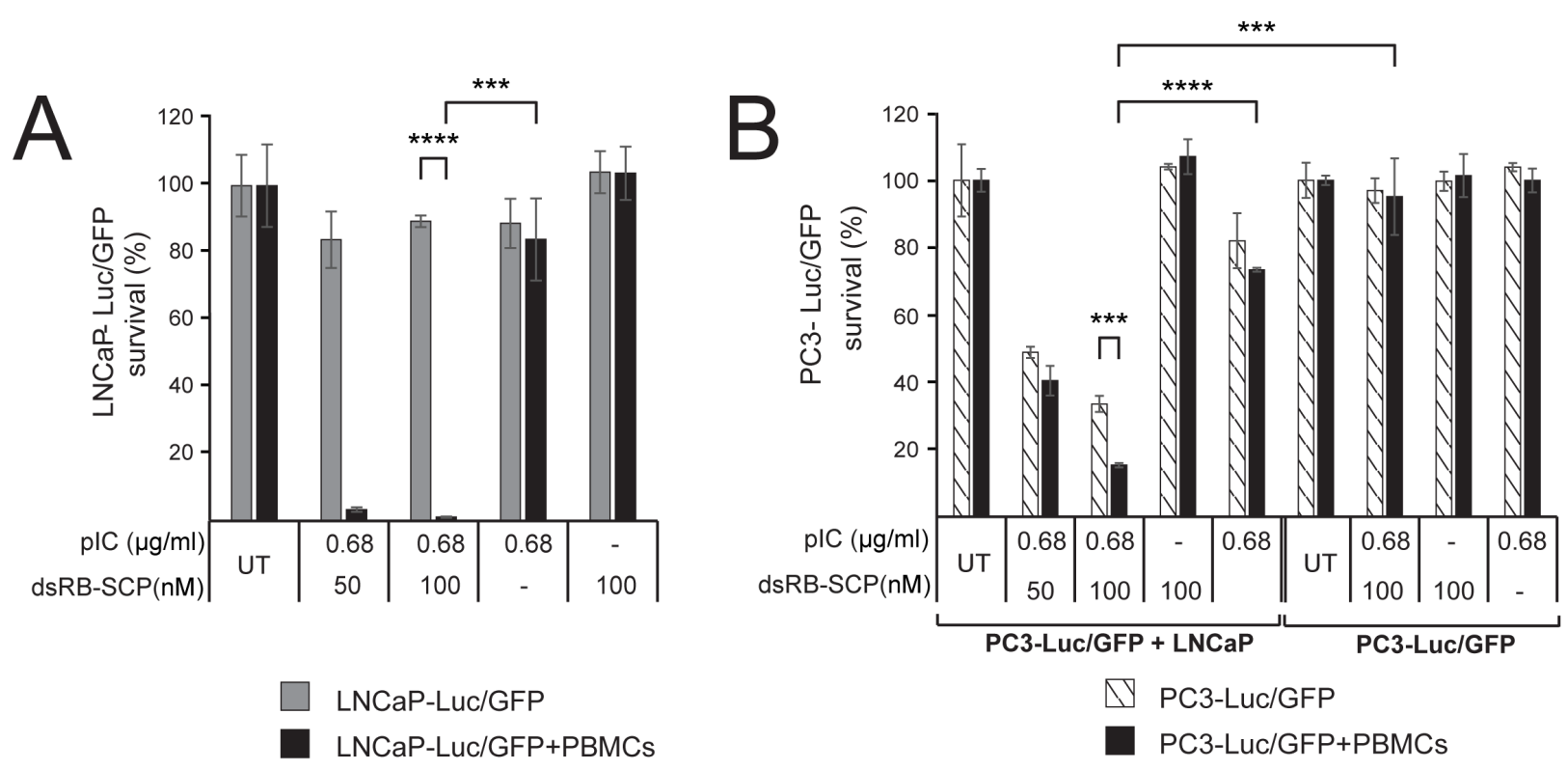

Figure 5: dsRB-SCP/polyIC induces direct and PBMC-mediated bystander effects. A. LNCaP-Luc/GFP cells were untreated or treated with dsRB-SCP/polyIC, polyIC alone or dsRB-SCP alone, as indicated. After $24 \mathrm{~h}, \mathrm{PBMCs}$ were added to the test wells (black bars), and medium without PBMCs was added to the control wells (gray bars). The survival of LNCaP-Luc/GFP cells was measured using the Luciferase Assay System (Promega) $(* * * * P \leq 0.0001$, LNCaP-Luc/GFP+PBMCs vs LNCaP-Luc/GFP, $* * * P \leq 0.001 \mathrm{dsRB}-\mathrm{SCP} /$ polyIC treatment vs polyIC alone). B. PC3-Luc/GFP cells co-cultured with PBMCs, in the presence or absence of LNCaP cells. PC3Luc/GFP+LNCaP: LNCaP cells were untreated or treated with dsRB-SCP/polyIC, dsRB-SCP alone or polyIC alone, as indicated. After $24 \mathrm{~h}, \mathrm{PC} 3$-Luc/GFP cells were added to the culture. $6 \mathrm{~h}$ later, PBMCs (black bars) or medium (hatched bars) was added to the culture. PC3-Luc/GFP: LNCaP growth medium, in the absence of cells, was untreated or treated with dsRB-SCP/polyIC, dsRB-SCP alone or polyIC alone, as indicated. After $24 \mathrm{~h}, \mathrm{PC} 3-\mathrm{Luc} / \mathrm{GFP}$ cells were added, and $6 \mathrm{~h}$ later either PBMCs (black bars) or medium (hatched bars) was added. The survival of PC3-Luc/GFP cells was measured using the Luciferase Assay System (Promega) (***P $\leq 0.001$, PC3$\mathrm{Luc} / \mathrm{GFP}+\mathrm{LNCaP}+\mathrm{PBMCs}$ vs PC3-Luc/GFP+LNCaP; ****P $\leq 0.0001 \mathrm{PC} 3-\mathrm{Luc} / \mathrm{GFP}+\mathrm{LNCaP}+\mathrm{PBMCs}$, dsRB-SCP/polyIC treatment vs polyIC alone; $* * * P \leq 0.001, \mathrm{PC} 3-\mathrm{Luc} / \mathrm{GFP}+\mathrm{LNCaP}+\mathrm{PBMCs}$ vs $\mathrm{PC} 3-\mathrm{Luc} / \mathrm{GFP}+\mathrm{PBMCs}$ ). Each experiment was conducted in triplicate. Representative data (mean and standard deviation) from three independent experiments are shown. 
5 , the spheroids that were treated with dsRB-SCP/polyIC began to shrink and shed dead cells, while the untreated spheroids continued to grow (Figure 6A). On day 15, the spheroids were stained with calcein AM and propidium iodide to monitor viability (Figure 6A). The dsRB$\mathrm{SCP} /$ polyIC-treated spheroids demonstrated significant structural damage and contained large numbers of dead cells (Figure 6A). In contrast, the untreated spheroids and spheroids treated with only polyIC or only dsRB-SCP, maintained a typical intact structure [23], where the cells at the surface were alive and the cells at the core were necrotic, as indicated by calcein-AM versus propidium iodide staining. (Figure 6A).

To test the immune-cell-mediated bystander effect
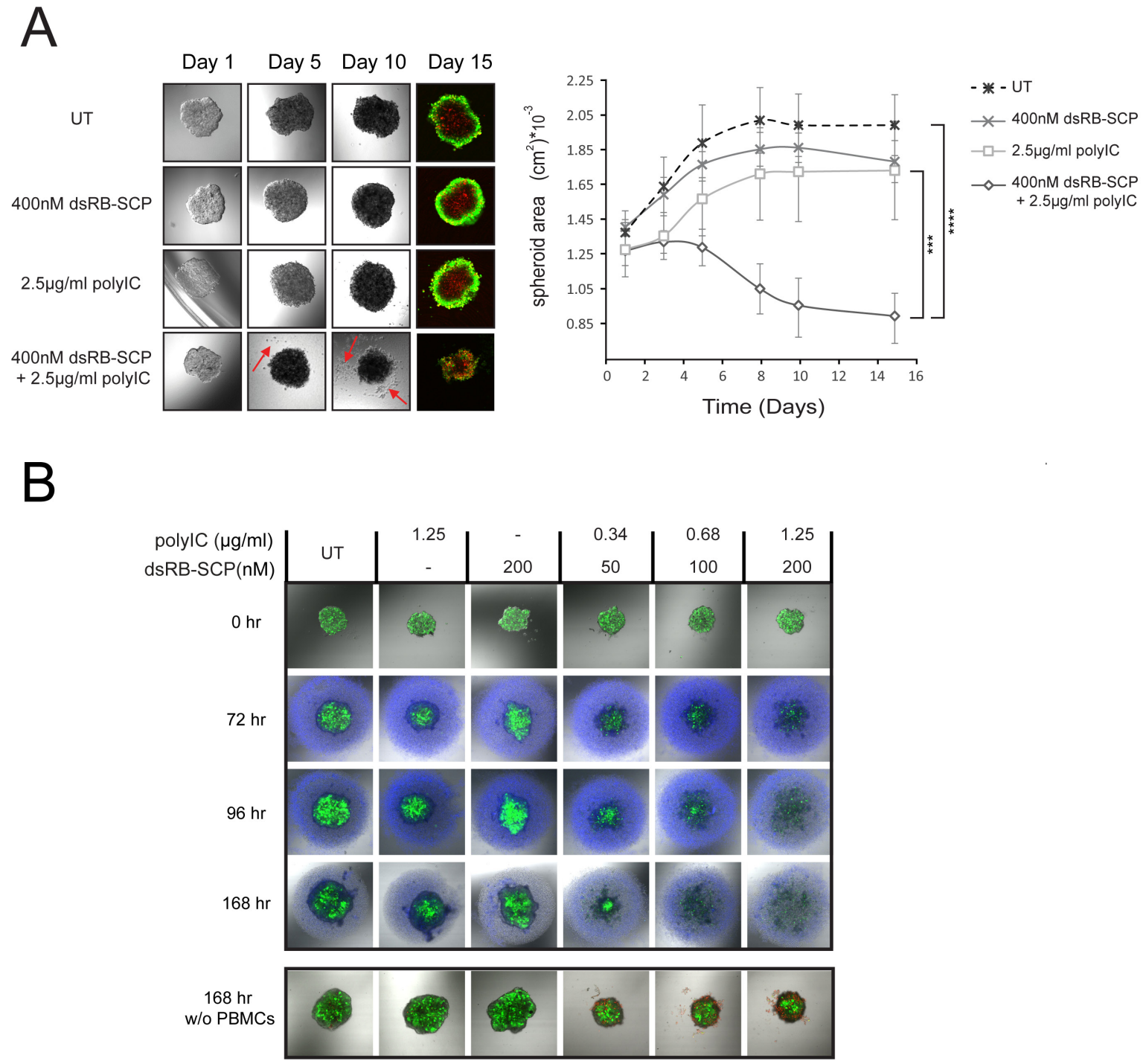

Figure 6: dsRB-SCP/polyIC treatment together with PBMCs leads to the destruction of LNCaP spheroids. A. Spheroids of 300-400 $\mu \mathrm{m}$ diameter were divided into four treatment groups $(n=4)$ : untreated (UT), dsRB-SCP alone, polyIC alone and dsRB-SCP/ polyIC. The spheroids were treated four times, on days 1, 2, 4 and 5, and then cultured for 10 additional days. Spheroid images were captured by laser scanning confocal microscopy at the indicated times; a series of 4 snapshots of a representative spheroid from each treatment group is shown. Note the prominent shedding of cells from the treated spheroid (red arrows). On Day 15, spheroids were labeled with Calcein AM (living cells; green) and Propidium Iodide (PI; dead cells; red). Areas of spheroids, measured using ImageJ, are shown in the graph (mean and standard deviation, $* * * * P \leq 0.0001 \mathrm{dsRB}-\mathrm{SCP} /$ polyIC treatment vs untreated cells, $* * * P \leq 0.001 \mathrm{dsRB}-\mathrm{SCP} /$ polyIC vs dsRB-SCP alone or polyIC alone). B. Upper panel: LNCaP-Luc/GFP spheroids of 300-400 $\mu$ m diameter were divided into six treatment groups, as indicated $(n=4)$. After 24 h, 8x10 $0^{4}$ PBCs labeled with CellTracker ${ }^{\mathrm{TM}}$ Violet BMQC (Invitrogen) were added to the spheroids. A series of snapshots of one representative spheroid per treatment is presented. Lower panel: PBMC medium without cells was added to the spheroids. Spheroids in both panels were captured by laser scanning confocal microscopy 0, 72, 96, $168 \mathrm{~h}$ after treatment initiation. Living cells were detected by their GFP fluorescence. Spheroid area was not quantified as the structure became totally diffuse shortly after the treatment began. PI was added to the spheroids in the lower panel, to highlight the dead cells. PI staining of upper panel is not shown, as there is no way to distinguish between dead LNCaP-Luc/GFP cells and dead PBMCs. The complete time course of the lower panel is shown in Supplementary Figure 2. 
Table 1: Oligonucleotides used for the construction of pGFP-SCP and dsRB-SCP.

\begin{tabular}{|l|l|}
\hline \multicolumn{1}{|c|}{ Name } & \multicolumn{1}{c|}{ Sequence 5' to 3' } \\
\hline SCP-N & TTTACTCGAGCGGAGGTGCAGCTGCAGC \\
\hline SCP-C & TTTTGCTCAGCGCCGTTACAGGTCC AGCCATG \\
\hline GFP-N & TTTTCATATGGTGAGCAAGGGCG \\
\hline GFP-C & TAAGGATCCGCCACCGCCGCTTTT CTTGTACAGC \\
\hline dsRB-N & TTTCATATGATGGCTGGTGATC \\
\hline dsRB-C & TTAGGATCCGCCACCGCCGCTCTCCGATAAGATC TGCAG \\
\hline 9ARG1 & GATCCCGTCGTCGCCGTCGTCGCCGTCGCGGCCGCAA \\
\hline 9ARG2 & AGCTTTGCGGCCGCGACGGCGACGACGGCGACGACGG \\
\hline
\end{tabular}

on the spheroids, we added PBMCs to treated spheroids. LNCaP-Luc/GFP spheroids were treated once with dsRB-SCP/polyIC, and 24 hours later freshly isolated PBMCs were added to the culture. Even at the lowest dose of dsRB-SCP/polyIC, spheroid disassembly was already evident 72 hours after the initiation of dsRB-SCP/ polyIC treatment (48 hours after PBMC addition) (Figure 6B upper panel). At higher doses, complete spheroid destruction was observed 96 hours after the initiation of the treatment. 72 hours later only dead cells, which showed no GFP fluorescence, were evident (Figure 6B upper panel). In the absence of PBMCs (Supplementary Figure 2), dsRB-SCP/polyIC treatment resulted in visible cell death and disassembly of the spheroid but the effect was weaker than in the presence of PBMCs (Figure 6B lower panel shows endpoint at 168 hours). Thus, dsRB$\mathrm{SCP} /$ polyIC has a potent effect on spheroids, and this effect is greatly magnified by the addition of immune cells.

\section{DISCUSSION}

There are currently no effective clinically approved treatment options for CRPC patients [2]. While PSMA is the target of choice for targeted treatment of prostate cancer in general and CRPC tumors in particular [44], no PSMA-targeted drugs have entered the clinic to date. Our therapy utilizes PSMA to facilitate the targeted delivery of polyIC into prostate cancer cells. PolyIC is a well-known anti-tumor immune adjuvant. However, its therapeutic window is limited due to its strong toxic side effects when delivered systemically [45]. By targeting polyIC to the tumor, systemic toxicity can be avoided [14]. Our strategy uses polyIC not only to directly kill cells that overexpress PSMA, but also to activate direct and immune-cell-mediated bystander effects, in order to eradicate heterogeneous tumors.

Our previous studies focused on the use of chemical vectors to target polyIC to EGFR- and HER2-overexpressing cancer cells [14, 33]. Proteins have several potential advantages as therapeutics over chemical compounds, as proteins function in a highly specific manner and feature consistent structures and low immunogenicity $[34,46]$. These advantages, as well as recent technical advancements in the field of protein engineering [47], motivated us to develop protein-based drugs. Here, we generated a novel chimeric protein, dsRBSCP, which can selectively deliver polyIC into PSMAoverexpressing cancer cells.

ScFvJ591 [29], the targeting moiety of our chimeric protein, was derived from the monoclonal antibody (mAb) J591, which recognizes the extracellular domain of PSMA [48]. mAb J591 has been used successfully in clinical studies. As an imaging tracer, mAb J591 linked to radionuclides ${ }^{89} \mathrm{Zr}$ or ${ }^{111} \mathrm{I}$ gave excellent results in the detection of bone lesions $[49,50]$. mAb J591 linked to ${ }^{177} \mathrm{Lu}$ was used in radio-immunotherapy to successfully target circulating tumor cells [20, 31]. mAb J591 was used to deliver the cytotoxic drug maytansinoid-1 (DM1) in a phase I clinical trial [21]. In all clinical applications, mAb J591 exhibited low immunogenicity. We chose to use the single-chain version of the full antibody, ScFvJ591, which consists of the variable regions of the heavy $(\mathrm{VH})$ and light (VL) chains of mAb J591, joined together by a flexible peptide linker [29]. This short single-chain version is easier to incorporate than the full antibody into an engineered chimeric protein expressed in bacteria [51]. Our GFP-SCP chimera entered PSMA-overexpressing cells rapidly and selectively, showing that both the single chain ScFvJ591 and the GFP were expressed in active conformations in the context of the recombinant fusion protein. The high specificity and affinity of the ScFvJ591containing chimeric protein are crucial for a potential therapy.

To construct a chimeric protein that would specifically bind and carry polyIC, we utilized the dsRNA binding domains (dsRBD1 and dsRBD2) isolated from the dsRNA-activated protein kinase (PKR). Previous studies showed that PKR has a high affinity for polyIC [52-54] and that isolated dsRBDs can facilitate the delivery of siRNA into cells [55]. Based on these reports we recently used the isolated dsRBDs to deliver polyIC to EGFtargeted cells successfully [56].

The expression and purification of a correctly folded, active chimeric protein is challenging. Here, we had the additional complication that the dsRB domain binds host nucleic acids [57]. We designed a purification process incorporating an unfolding and re-folding protocol, 
which successfully released the host nucleic acids [56]. We proved that the dsRB domain was functional using a gel mobility shift assay [58] (Figure 2C). Our purification process successfully generated purified dsRB-SCP with low batch-to-batch variations.

The immunostimulatory effect of polyIC is mainly mediated through the Toll-like Receptor3 (TLR3), which is part of the antiviral defense system. TLR3 is expressed on endosomal membranes and recognizes polyIC extracellularly [59]. Upon internalization, polyIC can escape from the endosomes into the cell cytosol, where it activates additional antiviral defense systems, including PKR, Retinoic acid-Inducible Gene I (RIG-1) and Melanoma Differentiation-Associated gene 5 (MDA5) [60]. To facilitate endosomal escape we inserted a peptide linker consisting of nine arginine residues, between the targeting and the polyIC-binding moieties. We chose the $\mathrm{Arg}_{9}$ peptide for two reasons. First, it is a synthetic derivative of HIV-I Tat protein, which is widely used as a membrane penetrating peptide. The peptide's high positive charge creates strong electrostatic interactions with the endosomal membrane, leading to its puncture $[35,36,61]$. Second, the $\mathrm{Arg}_{9}$ peptide contains a sequence that can be cleaved by furin, an endoprotease that is localized in the endosome [62]. The $\mathrm{Arg}_{9}$ sequence has been used to enable endosomal escape in the development of recombinant immunotoxins, with good results $[35,63]$.

dsRB-SCP was designed to bind polyIC via the dsRBD moiety, target prostate cancer cells using the ScFvJ591 moiety, and then release the polyIC cargo inside the endosome. To verify that the particles were small enough to enter the endosome (less than 200 $\mathrm{nm}$, according to Rejman et al. [64]), the complex was examined using cryo-transmission electron microscopy (Supplementary Figure 1). The acidic environment of the endosome influences the electrostatic interactions between the charged residues in the binding domain, as was shown with other dsRNA binding proteins[65]. dsRBSCP achieved high killing efficiency using low doses of polyIC (Figure 3A), which were ineffective in the absence of dsRB-SCP (Figure 3A). Paone et al. succeeded in triggering apoptosis in $\mathrm{LNCaP}$ cells using 10 -fold higher doses of naked PolyIC [66]. dsRB-SCP/polyIC triggered apoptosis specifically in PSMA-overexpressing cells within hours after internalization (Figure 3), fulfilling the criteria for effective therapy of selective and rapid action.

In addition to launching a strong direct attack on the targeted PSMA-overexpressing cancer cells, the strategy described here invokes a holistic approach to targeted therapy. Unlike kinase inhibitors, for example, which inhibit one or a small number of specific cancer driver molecules $[67,68]$, our therapy induces bystander effects that: (1) activate multiple killing pathways at the same time, thus preventing targeted cells from developing resistance and, (2) kill neighboring tumor cell subpopulations, overcoming the heterogeneous nature of tumors. These pathways activate the secretion of toxic cytokines (inducing a direct bystander effect) and the adaptive immune response (inducing an indirect, immunecell-mediated bystander effect) [60]. The bystander effects are mediated by the induction of cytokines such as IFN- $\beta$ (Figure $4 \mathrm{C}-4 \mathrm{D}$ ), and chemokines such as IP-10 and RANTES (Figure 4A-4B), known to be responsible for the attraction of monocytes and $\mathrm{T}$ lymphocytes $[69$, 70]. Indeed, medium from the treated cells successfully supported chemo-attraction of PBMCs (Figure 4E). dsRB-SCP successfully activated direct and immunecell-mediated bystander effects, amplifying the killing of PSMA-overexpressing cells and extending the effect to neighboring PSMA-negative cancer cells (Figure 5). These in vitro findings suggest that the treatment should be effective against heterogeneous tumors, in vivo.

To better predict the clinical efficacy of dsRB$\mathrm{SCP} /$ polyIC we used a tumor spheroid model. Cancer cells cultured as monolayers often show misleading sensitivity to therapeutic agents. Tumors feature cell-cell adhesion and three-dimensional shape, leading to "multicellular resistance" (MCR), which cannot be replicated in two-dimensional cultures [71]. Tumor cells cultured as spheroids present a multi-layer cell system that has many features of the three-dimensional tumor and therefore has greater potential to predict clinical efficacy $[43,72,73]$. Treatment of tumor spheroids with dsRB-SCP/polyIC resulted in visible structural damage (loss of integrity), probably due to the loss of adhesion between dead cells (Figure 6A). Adding immune cells to the spheroid model greatly amplified the response and accelerated the tumor disintegration time (Figure 6B). In both monolayer and spheroid cultures, the bystander effects were activated at extremely low doses of polyIC, suggesting that extensive tumor killing can be obtained in vivo, without toxic side effects.

In conclusion, we present a potent targeted therapy for metastatic prostate cancer, which leverages the antitumor effect of polyIC and delivers it specifically to cancer cells, using a novel chimeric recombinant protein vector. Our treatment demonstrates high effectiveness. It eradicates targeted and neighboring untargeted cancer cells in monolayer cultures, and rapidly and efficiently destroys tumor spheroids. It does so by activating apoptotic cancer cell death, as well as powerful direct and immune-cellmediated bystander effects. Our treatment has two major advantages in the clinical setting. First, it can be used with low doses of polyIC, especially in patients who are not immune compromised, thus minimizing polyIC toxicity [74]. Second, tumors are heterogeneous, with only some cells overexpressing PSMA. dsRB-SCP overcomes this challenge and holds promise of substantial efficacy, because of its ability to harness the immune system against the whole tumor and not only against the targeted subpopulations. 


\section{EXPERIMENTAL PROCEDURES}

\section{Cloning of GFP-SCP and dsRB-SCP}

Plasmids pGFP-SCP (encoding GFP linked via Arg 9 to the single chain antibody ScFvJ591 against PSMA; $56 \mathrm{kDa}$; Figure 1A) and pdsRB-SCP (encoding dsRB of human PKR linked via $\mathrm{Arg}_{9}$ to $\mathrm{ScFvJ} 591 ; 48 \mathrm{kDa}$; Figure 2A) were constructed as follows: SCP (single chain antibody against PSMA, ScFvJ591) was amplified by PCR from plasmid SFG-Pz1 [29], using primers SCP-N and SCP-C. GFP was amplified by PCR from plasmid pEGFP-N3 (Clontech), using primers GFP-N and GFP-C. dsRB was amplified by PCR from plasmid DRBM-DTEGF [56] using primers dsRB-N and dsRB-C. To prepare the $\mathrm{Arg}_{9}$ linker (GSRRRRRRRRGRKA), oligonucleotide 9ARG1 was annealed to its complementary oligonucleotide 9ARG2. The oligonucleotides used are listed in Table 1. GFP-SCP was constructed in several stages in the bacterial expression vector $\mathrm{pET} 28 \mathrm{a}$ (Novagen): GFP was cloned after the $\mathrm{His}_{6}$ tag of plasmid pET28a, between the NdeI and BamHI restriction sites, SCP was cloned between the HindIII and XhoI sites, and the $\operatorname{Arg}_{9}$ linker was inserted between the $B a m \mathrm{H} 1$ and HindIII sites, to give the fusion $\mathrm{His}_{6}-\mathrm{GFP}-\mathrm{Arg}_{9}-\mathrm{SCP}$ (Figure 1A and Supplementary Data). For the construction of dsRB-SCP, the GFP fragment was replaced with the dsRB sequence using restriction sites NdeI and BamHI, to give the fusion $\mathrm{His}_{6}$-dsRB-Arg ${ }_{9} \mathrm{SCP}$ (Figure 2A and Supplementary Data). The constructs were sequenced at The Center for Genomic Technologies at The Hebrew University of Jerusalem.

\section{Expression of GFP-SCP and dsRB-SCP}

The chimeric proteins were expressed in E. coli BL21trxB(DE3) (Novagen, Madison, WI, USA) which had been transformed with plasmid pRARE, which encodes tRNAs for rare codons. The bacteria were grown at $37^{\circ} \mathrm{C}$, in $2 \mathrm{XYT}$ medium, supplemented with $25 \mu \mathrm{g} /$ $\mathrm{ml}$ chloramphenicol, $30 \mu \mathrm{g} / \mathrm{ml}$ kanamycin, $100 \mu \mathrm{g} / \mathrm{ml}$ ampicillin, $1 \%$ glucose and $5 \%$ NPS buffer $\left(1 \mathrm{M} \mathrm{KH}_{2} \mathrm{PO}_{4}\right.$, $\left.1 \mathrm{M} \mathrm{Na}_{2} \mathrm{HPO}_{4}, 0.5 \mathrm{M}\left(\mathrm{NH}_{4}\right)_{2} \mathrm{SO}_{4}\right)$. When the culture reached $\mathrm{OD}_{600} \sim 0.3,0.1 \%$ glycerol and $0.1 \mathrm{mM}$ L-glutamic acid were added, and the culture was moved to $42{ }^{\circ} \mathrm{C}$, to induce the expression of $E$. coli chaperones and enhance protein solubility. When the culture reached O.D ${ }_{600} \sim 0.9$, it was cooled down on ice and transferred to $14{ }^{\circ} \mathrm{C}$. After a 10 minute adjustment period, IPTG was added to 0.5 $\mathrm{mmol} / \mathrm{L}$, followed by incubation for $24 \mathrm{~h}$ at $14{ }^{\circ} \mathrm{C}$. The bacteria were harvested and the pellet stored at $-80^{\circ} \mathrm{C}$ until purification.

\section{Purification of GFP-SCP and dsRB-SCP}

GFP-SCP: The pellet obtained from $1.2 \mathrm{~L}$ of E.coli BL21trxB(DE3, pRARE, pGFP-SCP) was thawed on ice in $60 \mathrm{ml}$ binding buffer (Buffer A, 30mM HEPES $\mathrm{pH} 8.3,0.5 \mathrm{M} \mathrm{NaCl}, 10 \%$ glycerol, $10 \mathrm{mM}$ imidazole) supplemented with a protease inhibitor cocktail, $3 \mathrm{mg} / \mathrm{ml}$ lysozyme and DNase, and lysed using a LV1 microfluidizer (Microfluidics, Newton, MA, USA). The extract was clarified by centrifugation for 30 minutes $\left(15,000 \times \mathrm{g}, 4^{\circ} \mathrm{C}\right)$, loaded onto an $8 \mathrm{ml}$ nickel sepharose FF IMAC column (GE Healthcare, Basel, Switzerland), and washed with 10 column volumes (CV) of binding buffer, followed by 6 $\mathrm{CV}$ of $5 \%$ Buffer B (30mM HEPES pH 8.3, 0.5M NaCl, $10 \%$ glycerol, $1 \mathrm{M}$ imidazole), $6 \mathrm{CV}$ of $10 \%$ Buffer B and $1 \mathrm{CV}$ of $15 \%$ Buffer B. The protein was eluted with $60 \%$ Buffer B. Fractions containing the chimera ( $8 \mathrm{ml}$ total) were loaded onto a $500 \mathrm{ml}$ Sephacryl S-200 gel filtration column (GE Healthcare) pre-equilibrated with GF buffer (30 mM HEPES pH 8.3, 0.5 M NaCl, 10\% glycerol). The fractions eluted after $0.5 \mathrm{CV}$ were pooled, concentrated using Vivaspin-20 (MWCO: 30000, GE Healthcare) and loaded onto $350 \mathrm{ml}$ Superdex-75. The fractions eluted after $0.5 \mathrm{CV}$ were subjected to SDS-PAGE and stained with InstantBlue (Expedeon, Harston, UK). The fractions that contained highly purified chimera were pooled, concentrated using Vivaspin-20, and stored in aliquots at $-80^{\circ} \mathrm{C}$.

dsRB-SCP: The pellet obtained from $6 \mathrm{~L}$ of E.coli BL21trxB(DE3, pRARE, pdsRB-SCP) was thawed in 300 $\mathrm{ml}$ binding buffer A supplemented with protease inhibitors, lysozyme and DNase, lysed and clarified as above. To release bound host nucleic acids, the cleared lysate was mixed 1:1 (vol:vol) with $8 \mathrm{M}$ urea. The mixture was incubated at $4{ }^{\circ} \mathrm{C}$ for 1.5 hours and then loaded onto $60 \mathrm{ml}$ nickel sepharose FF column pre-equilibrated with buffer C (Buffer A supplemented with $0.5 \%$ Tween 80 and $4 \mathrm{M}$ urea), and washed with $12.4 \mathrm{CV}$ Buffer $\mathrm{C}$. To refold the protein, a linear gradient of Buffer $\mathrm{C}$ to Buffer D (Buffer A supplemented with $0.5 \%$ Tween 80 ), $10 \mathrm{CV}, 0.8 \mathrm{ml} /$ min flow was applied. The column was washed with $3 \mathrm{CV}$ of $10 \%$ and $3 \mathrm{CV}$ of $25 \%$ Buffer E (30 mM HEPES pH $8.3,0.5 \mathrm{M} \mathrm{NaCl}, 10 \%$ glycerol, $500 \mathrm{mM}$ imidazole, $0.5 \%$ Tween 80 ), and the protein was eluted with $100 \%$ buffer E. The fractions containing the chimera were pooled and diluted 1:1 with dilution buffer (30 mM MES $\mathrm{pH}, 10 \%$ Glycerol, $0.5 \%$ Tween). The diluted protein was clarified by centrifugation for 30 minutes $\left(15,000 \times \mathrm{g}, 4^{\circ} \mathrm{C}\right)$ and loaded onto a $66 \mathrm{ml}$ Fracto-gel EMD SO3 IEX column (Merck, Darmstadt, Germany). A manual step gradient (7 $\mathrm{CV}$ ) of Buffer F (30 mM MES pH, $100 \mathrm{mM} \mathrm{NaCl}, 10 \%$ Glycerol, $0.001 \%$ Tween) and 25\%, 27\%, 30\%, 37\% and $38 \%$ Buffer G (30 mM HEPES pH 8.3, $2 \mathrm{M} \mathrm{NaCl}$, $10 \%$ glycerol, $0.001 \%$ Tween 80 ) was applied. Samples of the eluted fractions were subjected to SDS-PAGE and stained with InstantBlue. Fractions that contained purified 
chimera were pooled, concentrated, and stored at $-80^{\circ} \mathrm{C}$ as above. Judging from the InstantBlue stain (Figure 2B), the chimera was $>95 \%$ pure. The yield was $3.8 \mathrm{mg}$ protein from $6 \mathrm{~L}$ culture.

Cell lines LNCaP cells were cultured in RPMI 1640 medium supplemented with 10 mM HEPES pH 7.4 and $1 \mathrm{mM}$ sodium pyruvate. VCaP cells were cultured in DMEM (Dulbecco's Modified Eagle Medium). PC3 and DU145 cells were cultured in MEM (Minimum Essential Medium) supplemented with $1 \%$ non-essential amino acids, $1 \mathrm{mM}$ sodium pyruvate, $10 \mathrm{mM}$ Hepes $\mathrm{pH} 7.4$ and $1 \%$ MEM vitamin mixture. MCF7 cells were cultured in RPMI 1640 medium. All tissue culture media were supplemented with penicillin $(100 \mathrm{U} / \mathrm{ml})$, streptomycin (100 $\mathrm{mg} / \mathrm{l}$ ) and 10\% FBS (fetal bovine serum). All cell lines were purchased from the American Type Culture Collection (ATCC, Rockville, MD, USA), tested and shown to be mycoplasma-free. LNCaP-Luc/GFP and PC3-Luc/GFP were generated using lentiviral vectors encoding the fusion gene luciferase-GFP (Luc/GFP) as previously described [33]. PBMCs were isolated from fresh human peripheral blood by standard Ficoll densitygradient centrifugation [14]. All cells were incubated at 37 ${ }^{\circ} \mathrm{C}$ with $5 \% \mathrm{CO}_{2}$ in a humidified incubator. All cell culture reagents were purchased from Biological Industries, Bet Ha’emek, Israel.

\section{Flow cytometry}

Cells were plated onto 12-well plates at a density of $10^{5}$ cells per well, grown for 40 hours and incubated with GFP-SCP at $37^{\circ} \mathrm{C}$. After incubation, the cells were trypsinized, washed in PBS, re-suspended in $1 \mathrm{ml}$ cold PBS and subjected to flow cytometry analysis using BD FACS ARIAIII (BD Biosciences, USA) equipped with a $488 \mathrm{~nm}$ laser. 10,000 cells were acquired for each treatment. The cells were gated to include only live cells and the subpopulation was analyzed for GFP levels. All data were analyzed using FlowJo software (Becton Dickinson, Franklin Lakes, NJ, USA).

\section{Immunocytochemistry}

LNCaP, PC3 and MCF7 cells were grown for 48 hours and incubated with 25nM GFP-SCP for 5 hours at $37^{\circ} \mathrm{C}$. After incubation cells were fixed with $4 \%$ paraformaldehyde, washed twice with PBS, permeabilized and stained with goat anti-GFP antibody (1:1000, ab5450, Abcam, Cambridge, MA, USA ), followed by incubation with DyLight 488-conjugated anti-goat secondary antibody (1:300, Jackson ImmunoResearch Laboratories, West Grove, PA, USA). 4, 6-diamidino2-phenylindole (DAPI) was used to stain DNA. Stained samples were observed with a confocal microscope, FLUOVIEW FV-1000 (Olympus, Tokyo, Japan).

\section{Live cell imaging}

GFP-SCP localization was observed in live LNCaP cells, using time-lapse confocal microscopy (FLUOVIEW FV-1000). LNCaP cells were grown for 48 hours in 8-well $\mu$-slides (Ibidi, GmbH, Munich, Germany). After changing the medium, 200 nM GFPSCP was added directly to the chamber, the cells were immediately observed and subsequent images were taken every 6 minutes, for 72 minutes. The cells were incubated at $37^{\circ} \mathrm{C}$ with $5 \% \mathrm{CO}_{2}$, throughout the experiment. The images were analyzed using FLUOVIEW Viewer software (Ver.4.2)

\section{dsRNA Electrophoretic Mobility Shift Assay (EMSA)}

500 bp long dsRNA transcribed from the control template of the MEGAscript RNAi Kit (Ambion, Austin, TX, USA) was used to evaluate the binding of the purified protein to dsRNA. $1 \mu \mathrm{g}$ of dsRNA was incubated for 30 minutes with increasing amounts of purified dsRB-SCP (0.5-3 $\mu \mathrm{g})$ in binding buffer (30 mM HEPES pH 8.3, $0.5 \mathrm{M}$ $\mathrm{NaCl}, 10 \%$ glycerol $)$ or in acidic buffer $(0.5 \mathrm{M} \mathrm{K}$-acetate $\mathrm{pH} 5,10 \%$ glycerol), and the mixture was electrophoresed on a $2 \%$ agarose gel. The gel was visualized by staining with ethidium bromide.

\section{Preparation of dsRB-SCP/polyIC complex}

Low molecular weight (LMW) polyIC (InvivoGen, Toulouse, France) was used for all of the experiments. To prepare dsRB-SCP/polyIC, dsRB was pre-incubated with polyIC at the concentrations indicated in the text in binding buffer (30 mM HEPES pH 8.3, 0.5 M NaCl, $10 \%$ glycerol), for 45 minutes at room temperature, before addition to the cells. For controls, PolyIC and dsRB-SCP were each pre-incubated alone for 45 minutes at room temperature in binding buffer.

Complexes of dsRB-SCP/polyIC, polyIC alone and dsRB-SCP alone, prepared as above, were dialyzed for 1.5 hours against $30 \mathrm{mM}$ HEPES pH8.3, $0.5 \mathrm{M} \mathrm{NaCl}$ to remove the glycerol, using Slide-A-Lyzer MINI dialysis devices, 10K MWCO (Thermo Fisher Scientific Inc., MA, USA). For direct imaging using cryo-transmission electron microscopy (cryo-TEM), a drop $(3 \mu 1)$ of sample was placed on a glow discharged TEM grid (300-mesh $\mathrm{Cu}$ grid) pre-coated with a holey carbon film (Lacey substrate, Ted Pella Ltd., Redding CA, USA). To obtain a vitrified thin film, excess sample was drained using filter paper and the grid was immediately plunged into liquid ethane pre-cooled by liquid nitrogen, using a Vitrobot Mark IV (FEI Company, Hillsboro, OR, USA). Using a cold stage unit (Gatan model 626), the vitrified films were transferred 
to the electron microscope (FEI Tecnai 12 G2 TWIN, FEI Company, Hillsboro, OR, USA) and examined at -177 ${ }^{\circ} \mathrm{C}$. The images were recorded with a $4 \mathrm{k} x$ 4k FEI Eagle CCD camera in low dose mode and analyzed using Fiji image processing software.

\section{Survival assay}

LNCaP, VCaP, PC3 and MCF7 cells were seeded in 96-well plates in triplicate (5000 cells/well) and grown overnight. dsRB-SCP/polyIC, polyIC alone or dsRBSCP was added to the cells, which were then incubated for another 100 hours. Survival was measured using the CellTiter-Glo Luminescent Cell Viability Assay (Promega, Madison, WI, USA). To test whether the $\sim 20 \%$ of cells remaining after treatment were viable, $\mathrm{LNCaP}$ cells were seeded (5000 cells/well) in three 96 -well plates pre-coated with poly-lysine. For each plate, treatments were repeated in triplicate wells and the cells were grown overnight. The cells were then treated with dsRB-SCP/polyIC, polyIC alone or dsRB-SCP alone. The first plate was assayed for survival after 100 hours. The medium in the second plate was changed after 100 hours and survival was assayed after 172 hours. The medium in the third plate was changed after 100 hours and again after 172 hours and survival was assayed after 344 hours.

\section{Immunoblots}

LNCaP cells were seeded in 6-well plates $\left(10^{6}\right.$ cells/ well), grown overnight and treated with dsRB-SCP/polyIC or polyIC alone at the indicated concentrations. After 7 , 16 or 24 hours cells were lysed with boiling Laemmli sample buffer $(10 \%$ glycerol, $50 \mathrm{mmol} / \mathrm{L}$ Tris- $\mathrm{HCl}, \mathrm{pH}$ $6.8,3 \% \mathrm{SDS}$, and 5\% 2-mercaptoethanol) and the lysates were then subjected to western blot analysis [75]. The cleavage of PARP and caspase-3 was monitored using anti-PARP (cat\#95425), anti-caspase3 (cat\#96625) and anti-cleaved caspase-3 (cat\#96615) (all from Cell Signaling Technology, Beverly, MA, USA). As an internal control to normalize the amount of protein applied in each lane the blots were also incubated with anti-GAPDH (sc25778, Santa Cruz Biotechnology, Santa Cruz CA, USA).

\section{Detection of secreted chemokines (IP-10 and RANTES) by ELISA}

LNCaP cells were seeded in 96-well plates in triplicate and grown overnight (10,000 cells/well). Cells were then treated with dsRB-SCP/polyIC or polyIC alone at the indicated concentrations. After 48 hours the medium was collected and the concentrations of IP-10, RANTES and IFN- $\beta$ were measured using commercial ELISA kits. IP-10 and RANTES were measured using PeproTech ELISA kits from PeproTech (Rocky Hill, NJ, USA) and IFN- $\beta$ was measured using LumiKine hIFN- $\beta$ kit (InvivoGen, Toulouse, France).

\section{RNA isolation, cDNA synthesis and quantitative real-time PCR}

LNCaP cells were seeded in 24-well plates $(500,000$ cells per well) and grown overnight. Cells were then treated for 4 hours with dsRB-SCP/polyIC, polyIC alone or dsRB-SCP alone at the indicated concentrations. The cells were lysed and total RNA was extracted using the EZ-10 DNA Away RNA-Miniprep Kit (Bio Basic, Toronto, Canada). Complementary DNA (cDNA) was synthesized using the High Capacity cDNA Reverse Transcription Kit (Applied Biosystems, Foster City, CA, USA). IFN- $\beta$ gene expression levels were compared using quantitative realtime PCR and normalized to GAPDH expression using the $\Delta \Delta \mathrm{CT}$ method. The primers for IFN- $\beta$ quantification were: forward: 5' ATGACCAACAAGTGTCTCCTCC 3' and reverse: 5' GCTCATGGAAAGAGCTGTAGTG 3'. The primers for GAPDH quantification were forward: 5' GAGCCACATCGCTCAGAC 3' and reverse: 5' CTTCTCATGGTTCACACCC 3'.

Chemotaxis of PBMCs LNCaP cells were seeded in 24-well plates pre-coated with poly-lysine $(250,000$ cells/well) and grown overnight. Then, the medium was replaced by low-serum medium $(0.15 \%$ FBS $)$ and the cells were treated with dsRB-SCP/polyIC at the indicated concentrations. After 48 hours conditioned medium was collected from the cells and placed in the bottom well of a 24-well Transwell system (microporous polycarbonate membrane $(0.5 \mu \mathrm{m})$, CorningCostar Corp., Cambridge, MA, USA). Freshly isolated PBMCs $\left(1 \times 10^{6}\right)$ in low-serum medium $(0.15 \%$ FBS $)$ were added to the upper chamber. After 3.5 hours, medium from the lower chamber was collected and the migrated cells were quantified by FACS analysis, scatter-gating on lymphocytes.

\section{Analysis of bystander effects in co-culture systems}

In order to measure the viability of a single cell line in co-culture with other cells, we generated cells that expressed luciferase (either LNCaP-Luc/GFP or PC3-Luc/ GFP).

The immune-cell-mediated bystander effect was analyzed using LNCaP-Luc/GFP cells co-cultured with PBMCs: LNCaP-Luc/GFP cells were seeded in triplicate in 96-well plates pre-coated with poly-lysine (10,000 cells/ well) and grown overnight. The cells were then treated with dsRB-SCP/polyIC, polyIC alone or dsRB-SCP alone at the indicated concentrations. After 24 hours, freshly isolated PBMCs were added to the culture $\left(1 \mathrm{X} 10^{5} \mathrm{per}\right.$ well). 48 hours later, the survival of LNCaP-Luc/GFP cells was measured based on luciferase activity using the Luciferase Assay System. 
The combined direct and immune-cell-mediated bystander effect was analyzed using $\mathrm{LNCaP}$ cells cocultured with PC3-Luc/GFP and PBMCs: LNCaP cells were seeded in triplicate in 96-well plates pre-coated with poly-lysine $(6,000$ cells/well) and grown overnight, and the cells were treated with dsRB-SCP/polyIC, polyIC alone or dsRB-SCP alone. After 16 hours PC3-Luc/GFP cells $(4,000$ cells/ well $)$ were added to the culture. Eight hours later, i.e. 24 hours after treatment initiation, freshly isolated PBMCs $\left(1 \mathrm{X} 10^{5} /\right.$ well) were added to the culture. 48 hours later survival of the PC3-Luc/GFP cells was measured based on luciferase activity, using the Luciferase Assay system.

\section{Tumor spheroid model}

Tumor spheroids were generated using agar-coated plates. 96-well plates were coated with $50 \mu \mathrm{l} /$ well agar $(1.5 \%(\mathrm{wt} / \mathrm{vol})$ dissolved in RPMI) as described by Friedrich, et al. [76]. LNCaP or LNCaP-Luc/GFP cells were seeded (2000 cells per well) and incubated at $37^{\circ} \mathrm{C}$ in $5 \% \mathrm{CO}_{2}$. After 97 hours, a single spherical spheroid $300-400 \mu \mathrm{m}$ diameter had formed in each well.

To measure $\mathrm{LNCaP}$ spheroids following treatment with dsRB-SCP/polyIC, we transferred the spheroids individually to 96 -well plates (1 spheroid/well) pre-coated with a very thin, even layer of polyHEMA (Sigma, St Louis, MI, USA) (120 $\mathrm{mg} / \mathrm{ml}$ dissolved in $95 \%$ ethanol). To transfer the spheroids, we first lifted each spheroid together with its $200 \mu 1$ of medium into a 96U-well plate (with U-shaped wells). The plate was centrifuged for 10 minutes at $220 \mathrm{~g}$ and the medium was replaced with 80 $\mu \mathrm{l}$ of fresh medium. The spheroid was then transferred, together with its $80 \mu \mathrm{l}$ of medium, to the polyHEMAcoated plate. dsRB-SCP/polyIC, polyIC alone or dsRBSCP alone were added at the indicated concentrations. Treatment continued for 5 days. On days 1, 2, 4 and 5, half of the medium in each well was removed and replaced with fresh medium containing the appropriate treatment. On Day 15, spheroids were stained with calcein AM (1:1000, c3099, Molecular Probes, Eugene, OR, USA) and $0.5 \mu \mathrm{g} / \mathrm{ml}$ propidium iodide. Spheroids were monitored using confocal microscopy and size was measured using Image J software.

To analyze the immune-cell-mediated bystander effects on tumor spheroids, we treated LNCaP-Luc/GFP spheroids once, directly on the agar plate, with dsRB-SCP/ polyIC, polyIC alone or dsRB-SCP alone at the indicated concentrations. After 24 hours fresh PBMCs were labeled using $1 \mu \mathrm{M}$ CellTrackerTM Violet BMQC (Invitrogen, San Diego, CA, USA) according to the manufacturer's protocol. $8 \times 10^{4}$ PBMCs were added to the spheroid culture. The co-culture was monitored using confocal microscopy

\section{Statistical analysis}

Statistical analyses were performed using unpaired t-test to compare the difference between two group's means. $\mathrm{P}$ value indicates the probability of a significant difference between two means, where $P \leq 0.05$ was considered as a significant difference.

\section{ACKNOWLEDGMENTS}

We acknowledge the technical assistance of Orit Berhani and Aviva Petcho, and thank Prof. Michel Sadelain for the gift of the plasmid encoding the single chain antibody.

\section{GRANT SUPPORT}

ISF grant no. 1556/13 (A. Levitzki), ERC Advanced Grant No. 249898 (A. Levitzki).

\section{CONFLICT OF INTEREST}

The authors declare no conflict of interests.

\section{REFERENCES}

1. Siegel RL, Miller KD, Jemal A. Cancer statistics, 2016. CA Cancer J Clin. 2016; 66:7-30.

2. Attard G, Sarker D, Reid A, Molife R, Parker C, de Bono JS. Improving the outcome of patients with castrationresistant prostate cancer through rational drug development. Br J Cancer. 2006; 95:767-74.

3. Javidan J, Deitch AD, Shi XB, de Vere White RW. The androgen receptor and mechanisms for androgen independence in prostate cancer. Cancer Invest. 2005; 23:520-28.

4. Luo J, Beer TM, Graff JN. Treatment of Nonmetastatic Castration-Resistant Prostate Cancer. Oncology (Williston Park). 2016; 30:336-44.

5. Kumaravel TS, Bristow RG. Detection of genetic instability at HER-2/neu and p53 loci in breast cancer cells sing Comet-FISH. Breast Cancer Res Treat. 2005; 91:89-93.

6. Rajagopalan H, Jallepalli PV, Rago C, Velculescu VE, Kinzler KW, Vogelstein B, Lengauer C. Inactivation of hCDC4 can cause chromosomal instability. Nature. 2004; 428:77-81.

7. Lengauer C, Kinzler KW, Vogelstein B. Genetic instability in colorectal cancers. Nature. 1997; 386:623-27.

8. Gottesman MM, Fojo T, Bates SE. Multidrug resistance in cancer: role of ATP-dependent transporters. Nat Rev Cancer. 2002; 2:48-58.

9. Shattuck DL, Miller JK, Carraway KL 3rd, Sweeney C. Met receptor contributes to trastuzumab resistance of Her2- 
overexpressing breast cancer cells. Cancer Res. 2008; 68:1471-77.

10. Zahreddine H, Borden KL. Mechanisms and insights into drug resistance in cancer. Front Pharmacol. 2013; 4:28.

11. Wyatt AW, Mo F, Wang K, McConeghy B, Brahmbhatt S, Jong L, Mitchell DM, Johnston RL, Haegert A, Li E, Liew J, Yeung J, Shrestha R, et al. Heterogeneity in the intertumor transcriptome of high risk prostate cancer. Genome Biol. 2014; 15:426.

12. Andor N, Graham TA, Jansen M, Xia LC, Aktipis CA, Petritsch C, Ji HP, Maley CC. Pan-cancer analysis of the extent and consequences of intratumor heterogeneity. Nat Med. 2016; 22:105-13.

13. Hao JJ, Lin DC, Dinh HQ, Mayakonda A, Jiang YY, Chang C, Jiang Y, Lu CC, Shi ZZ, Xu X, Zhang Y, Cai Y, Wang JW, et al. Spatial intratumoral heterogeneity and temporal clonal evolution in esophageal squamous cell carcinoma. Nat Genet. 2016; 48:1500-07.

14. Shir A, Ogris M, Roedl W, Wagner E, Levitzki A. EGFRhoming dsRNA activates cancer-targeted immune response and eliminates disseminated EGFR-overexpressing tumors in mice. Clin Cancer Res. 2011; 17:1033-43.

15. Bostwick DG, Pacelli A, Blute M, Roche P, Murphy GP. Prostate specific membrane antigen expression in prostatic intraepithelial neoplasia and adenocarcinoma: a study of 184 cases. Cancer. 1998; 82:2256-61.

16. Akhtar NH, Pail O, Saran A, Tyrell L, Tagawa ST. Prostatespecific membrane antigen-based therapeutics. Adv Urol. 2012; 2012:973820.

17. Sweat SD, Pacelli A, Murphy GP, Bostwick DG. Prostatespecific membrane antigen expression is greatest in prostate adenocarcinoma and lymph node metastases. Urology. 1998; 52:637-40.

18. Wright GL Jr, Grob BM, Haley C, Grossman K, Newhall K, Petrylak D, Troyer J, Konchuba A, Schellhammer PF, Moriarty R. Upregulation of prostate-specific membrane antigen after androgen-deprivation therapy. Urology. 1996; 48:326-34.

19. Mannweiler S, Amersdorfer P, Trajanoski S, Terrett JA, King D, Mehes G. Heterogeneity of prostate-specific membrane antigen (PSMA) expression in prostate carcinoma with distant metastasis. Pathol Oncol Res. 2009; 15:167-72.

20. Tagawa ST, Milowsky MI, Morris M, Vallabhajosula S, Christos P, Akhtar NH, Osborne J, Goldsmith SJ, Larson S, Taskar NP, Scher HI, Bander NH, Nanus DM. Phase II study of Lutetium-177-labeled anti-prostate-specific membrane antigen monoclonal antibody J591 for metastatic castration-resistant prostate cancer. Clin Cancer Res. 2013; 19:5182-91.

21. Galsky MD, Eisenberger M, Moore-Cooper S, Kelly WK, Slovin SF, DeLaCruz A, Lee Y, Webb IJ, Scher HI. Phase I trial of the prostate-specific membrane antigen-directed immunoconjugate MLN2704 in patients with progressive metastatic castration-resistant prostate cancer. J Clin Oncol. 2008; 26:2147-54.

22. van Leeuwen PJ, Stricker P, Hruby G, Kneebone A, Ting F, Thompson B, Nguyen Q, Ho B, Emmett L. (68) Ga-PSMA has a high detection rate of prostate cancer recurrence outside the prostatic fossa in patients being considered for salvage radiation treatment. BJU Int. 2016; 117:732-39.

23. Phung YT, Barbone D, Broaddus VC, Ho M. Rapid generation of in vitro multicellular spheroids for the study of monoclonal antibody therapy. J Cancer. 2011; 2:507-14.

24. Liu H, Rajasekaran AK, Moy P, Xia Y, Kim S, Navarro V, Rahmati R, Bander NH. Constitutive and antibody-induced internalization of prostate-specific membrane antigen. Cancer Res. 1998; 58:4055-60.

25. Kularatne SA, Zhou Z, Yang J, Post CB, Low PS. Design, synthesis, and preclinical evaluation of prostate-specific membrane antigen targeted $(99 \mathrm{~m})$ Tc-radioimaging agents. Mol Pharm. 2009; 6:790-800.

26. Eder M, Schäfer M, Bauder-Wüst U, Hull WE, Wängler C, Mier W, Haberkorn U, Eisenhut M. 68Ga-complex lipophilicity and the targeting property of a urea-based PSMA inhibitor for PET imaging. Bioconjug Chem. 2012; 23:688-97.

27. Pandit-Taskar N, O’Donoghue JA, Durack JC, Lyashchenko SK, Cheal SM, Beylergil V, Lefkowitz RA, Carrasquillo JA, Martinez DF, Fung AM, Solomon SB, Gönen M, Heller G, et al. A Phase I/II Study for Analytic Validation of 89Zr-J591 ImmunoPET as a Molecular Imaging Agent for Metastatic Prostate Cancer. Clin Cancer Res. 2015; 21:5277-85.

28. Wolf P, Gierschner D, Bühler P, Wetterauer U, ElsässerBeile U. A recombinant PSMA-specific single-chain immunotoxin has potent and selective toxicity against prostate cancer cells. Cancer Immunol Immunother. 2006; 55:1367-73.

29. Gong MC, Latouche JB, Krause A, Heston WD, Bander $\mathrm{NH}$, Sadelain M. Cancer patient T cells genetically targeted to prostate-specific membrane antigen specifically lyse prostate cancer cells and release cytokines in response to prostate-specific membrane antigen. Neoplasia. 1999; $1: 123-27$.

30. Bander NH, Milowsky MI, Nanus DM, Kostakoglu L, Vallabhajosula S, Goldsmith SJ. Phase I trial of 177lutetium-labeled J591, a monoclonal antibody to prostate-specific membrane antigen, in patients with androgen-independent prostate cancer. J Clin Oncol. 2005; 23:4591-601.

31. Vallabhajosula S, Nikolopoulou A, Jhanwar YS, Kaur G, Tagawa ST, Nanus DM, Bander NH, Goldsmith SJ. Radioimmunotherapy of Metastatic Prostate Cancer with ${ }^{177}$ Lu-DOTAhuJ591 Anti Prostate Specific Membrane Antigen Specific Monoclonal Antibody. Curr Radiopharm. 2016; 9:44-53.

32. Shir A, Ogris M, Wagner E, Levitzki A. EGF receptor- 
targeted synthetic double-stranded RNA eliminates glioblastoma, breast cancer, and adenocarcinoma tumors in mice. PLoS Med. 2006; 3:e6.

33. Zigler M, Shir A, Joubran S, Sagalov A, Klein S, Edinger N, Lau J, Yu SF, Mizraji G, Globerson Levin A, Sliwkowski MX, Levitzki A. HER2-Targeted Polyinosine/Polycytosine Therapy Inhibits Tumor Growth and Modulates the Tumor Immune Microenvironment. Cancer Immunol Res. 2016.

34. Leader B, Baca QJ, Golan DE. Protein therapeutics: a summary and pharmacological classification. Nat Rev Drug Discov. 2008; 7:21-39.

35. He D, Yang H, Lin Q, Huang H. Arg9-peptide facilitates the internalization of an anti-CEA immunotoxin and potentiates its specific cytotoxicity to target cells. Int J Biochem Cell Biol. 2005; 37:192-205.

36. Wender PA, Mitchell DJ, Pattabiraman K, Pelkey ET, Steinman L, Rothbard JB. The design, synthesis, and evaluation of molecules that enable or enhance cellular uptake: peptoid molecular transporters. Proc Natl Acad Sci USA. 2000; 97:13003-08.

37. Santoro SP, Kim S, Motz GT, Alatzoglou D, Li C, Irving M, Powell DJ Jr, Coukos G. T cells bearing a chimeric antigen receptor against prostate-specific membrane antigen mediate vascular disruption and result in tumor regression. Cancer Immunol Res. 2015; 3:68-84.

38. Peisley A, Lin C, Wu B, Orme-Johnson M, Liu M, Walz T, Hur S. Cooperative assembly and dynamic disassembly of MDA5 filaments for viral dsRNA recognition. Proc Natl Acad Sci USA. 2011; 108:21010-15.

39. Der SD, Lau AS. Involvement of the double-strandedRNA-dependent kinase PKR in interferon expression and interferon-mediated antiviral activity. Proc Natl Acad Sci USA. 1995; 92:8841-45.

40. Kumar A, Zhang J, Yu FS. Toll-like receptor 3 agonist poly(I:C)-induced antiviral response in human corneal epithelial cells. Immunology. 2006; 117:11-21.

41. Galli R, Starace D, Busà R, Angelini DF, Paone A, De Cesaris P, Filippini A, Sette C, Battistini L, Ziparo E, Riccioli A. TLR stimulation of prostate tumor cells induces chemokine-mediated recruitment of specific immune cell types. J Immunol. 2010; 184:6658-69.

42. Kim JB. Three-dimensional tissue culture models in cancer biology. Semin Cancer Biol. 2005; 15:365-77.

43. Takagi A, Watanabe M, Ishii Y, Morita J, Hirokawa Y, Matsuzaki T, Shiraishi T. Three-dimensional cellular spheroid formation provides human prostate tumor cells with tissue-like features. Anticancer Res. 2007; 27:45-53.

44. Silver DA, Pellicer I, Fair WR, Heston WD, Cordon-Cardo C. Prostate-specific membrane antigen expression in normal and malignant human tissues. Clin Cancer Res. 1997; 3:8185.

45. Krown SE, Kerr D, Stewart WE 2nd, Field AK, Oettgen HF. Phase I trials of poly(I,C) complexes in advanced cancer. J Biol Response Mod. 1985; 4:640-49.
46. Huang $\mathrm{CJ}$, Lin $\mathrm{H}$, Yang $\mathrm{X}$. Industrial production of recombinant therapeutics in Escherichia coli and its recent advancements. J Ind Microbiol Biotechnol. 2012; 39:38399.

47. Carter PJ. Introduction to current and future protein therapeutics: a protein engineering perspective. Exp Cell Res. 2011; 317:1261-69.

48. Liu H, Moy P, Kim S, Xia Y, Rajasekaran A, Navarro V, Knudsen B, Bander NH. Monoclonal antibodies to the extracellular domain of prostate-specific membrane antigen also react with tumor vascular endothelium. Cancer Res. 1997; 57:3629-34.

49. Pandit-Taskar N, O’Donoghue JA, Durack JC, Lyashchenko SK, Cheal SM, Beylergil V, Lefkowitz RA, Carrasquillo JA, Martinez DF, Fung AM, Solomon SB, Gönen M, Heller G, et al. A Phase I/II Study for Analytic Validation of 89Zr-J591 ImmunoPET as a Molecular Imaging Agent for Metastatic Prostate Cancer. Clin Cancer Res. 2015; 21:5277-85.

50. Pandit-Taskar N, O’Donoghue JA, Divgi CR, Wills EA, Schwartz L, Gönen M, Smith-Jones P, Bander NH, Scher HI, Larson SM, Morris MJ. Indium 111-labeled J591 anti-PSMA antibody for vascular targeted imaging in progressive solid tumors. EJNMMI Res. 2015; 5:28.

51. Ahmad ZA, Yeap SK, Ali AM, Ho WY, Alitheen NB, Hamid M. scFv antibody: principles and clinical application. Clin Dev Immunol. 2012; 2012:980250.

52. Tian B, Mathews MB. Functional characterization of and cooperation between the double-stranded RNA-binding motifs of the protein kinase PKR. J Biol Chem. 2001; 276:9936-44.

53. Gunnery S, Mathews MB. RNA binding and modulation of PKR activity. Methods. 1998; 15:189-98.

54. Patel S, Blose JM, Sokoloski JE, Pollack L, Bevilacqua PC. Specificity of the double-stranded RNA-binding domain from the RNA-activated protein kinase PKR for doublestranded RNA: insights from thermodynamics and smallangle X-ray scattering. Biochemistry. 2012; 51:9312-22.

55. Eguchi A, Meade BR, Chang YC, Fredrickson CT, Willert K, Puri N, Dowdy SF. Efficient siRNA delivery into primary cells by a peptide transduction domain-dsRNA binding domain fusion protein. Nat Biotechnol. 2009; 27:567-71.

56. Edinger N, Lebendiker M, Klein S, Zigler M, Langut Y, Levitzki A. Targeting polyIC to EGFR over-expressing cells using a dsRNA binding protein domain tethered to EGF. PLoS One. 2016; 11:e0162321.

57. Fenner BJ, Goh W, Kwang J. Sequestration and protection of double-stranded RNA by the betanodavirus b2 protein. J Virol. 2006; 80:6822-33.

58. Zheng X, Bevilacqua PC. Straightening of bulged RNA by the double-stranded RNA-binding domain from the protein kinase PKR. Proc Natl Acad Sci USA. 2000; 97:14162-67.

59. Salem ML, El-Naggar SA, Kadima A, Gillanders WE, Cole 
DJ. The adjuvant effects of the toll-like receptor 3 ligand polyinosinic-cytidylic acid poly (I:C) on antigen-specific CD8 + T cell responses are partially dependent on NK cells with the induction of a beneficial cytokine milieu. Vaccine. 2006; 24:5119-32.

60. Levitzki A. Targeting the Immune System to Fight Cancer Using Chemical Receptor Homing Vectors Carrying Polyinosine/Cytosine (PolyIC). Front Oncol. 2012; 2:4.

61. Futaki S, Suzuki T, Ohashi W, Yagami T, Tanaka S, Ueda K, Sugiura Y. Arginine-rich peptides. An abundant source of membrane-permeable peptides having potential as carriers for intracellular protein delivery. J Biol Chem. 2001; 276:5836-40.

62. Hosaka M, Nagahama M, Kim WS, Watanabe T, Hatsuzawa K, Ikemizu J, Murakami K, Nakayama K. Arg-X-Lys/ Arg-Arg motif as a signal for precursor cleavage catalyzed by furin within the constitutive secretory pathway. J Biol Chem. 1991; 266:12127-30.

63. Wang T, Zhao J, Ren JL, Zhang L, Wen WH, Zhang R, Qin WW, Jia LT, Yao LB, Zhang YQ, Chen SY, Yang AG. Recombinant immunoproapoptotic proteins with furin site can translocate and kill HER2-positive cancer cells. Cancer Res. 2007; 67:11830-39.

64. Rejman J, Oberle V, Zuhorn IS, Hoekstra D. Size-dependent internalization of particles via the pathways of clathrin- and caveolae-mediated endocytosis. Biochem J. 2004; 377:15969.

65. Koukiekolo R, Sagan SM, Pezacki JP. Effects of $\mathrm{pH}$ and salt concentration on the siRNA binding activity of the RNA silencing suppressor protein p19. FEBS Lett. 2007; 581:3051-56.

66. Paone A, Starace D, Galli R, Padula F, De Cesaris P, Filippini A, Ziparo E, Riccioli A. Toll-like receptor 3 triggers apoptosis of human prostate cancer cells through a PKC-alpha-dependent mechanism. Carcinogenesis. 2008; 29:1334-42.
67. Imai K, Takaoka A. Comparing antibody and smallmolecule therapies for cancer. Nat Rev Cancer. 2006; 6:714-27.

68. Cree IA, Charlton P. Molecular chess? Hallmarks of anticancer drug resistance. BMC Cancer. 2017; 17:10.

69. Schall TJ, Bacon K, Toy KJ, Goeddel DV. Selective attraction of monocytes and T lymphocytes of the memory phenotype by cytokine RANTES. Nature. 1990; 347:66971.

70. Huang H, Xiang J. Synergistic effect of lymphotactin and interferon gamma-inducible protein-10 transgene expression in T-cell localization and adoptive T-cell therapy of tumors. Int J Cancer. 2004; 109:817-25.

71. Minchinton AI, Tannock IF. Drug penetration in solid tumours. Nat Rev Cancer. 2006; 6:583-92.

72. Hirschhaeuser F, Menne H, Dittfeld C, West J, MuellerKlieser W, Kunz-Schughart LA. Multicellular tumor spheroids: an underestimated tool is catching up again. $\mathrm{J}$ Biotechnol. 2010; 148:3-15.

73. Chambers KF, Mosaad EM, Russell PJ, Clements JA, Doran MR 3rd. 3D Cultures of prostate cancer cells cultured in a novel high-throughput culture platform are more resistant to chemotherapeutics compared to cells cultured in monolayer. PLoS One. 2014; 9:e111029.

74. Cheng YS, Xu F. Anticancer function of polyinosinicpolycytidylic acid. Cancer Biol Ther. 2010; 10:1219-23.

75. Mizrachy-Schwartz S, Cohen N, Klein S, KravchenkoBalasha N, Levitzki A. Up-regulation of AMP-activated protein kinase in cancer cell lines is mediated through c-Src activation. J Biol Chem. 2011; 286:15268-77.

76. Friedrich J, Seidel C, Ebner R, Kunz-Schughart LA. Spheroid-based drug screen: considerations and practical approach. Nat Protoc. 2009; 4:309-24. 